\title{
The Unintended Consequences of Flexicurity: The Health Consequences of Flexible Employment
}

\author{
Keith A. Bender* Ioannis Theodossiou \\ Department of Economics and Centre for European Labour Market Research \\ University of Aberdeen \\ Aberdeen AB24 3QY \\ Scotland, UK
}

Keywords: health, flexible contracts, atypical employment, flexicurity

JEL- Code: J24, J22

\begin{abstract}
While atypical employment contracts offer flexibility in the labour market, these kinds of contracts are inherently insecure and may generate stress among affected workers. This study examines the impact of atypical forms of employment (specifically seasonal or temporary jobs or a fixed time contracts) on workers' health. Survival analysis shows that, other things equal, the longer percent of time spent in flexible employment contracts increases the odds of falling into ill health for a variety of health conditions. The results are robust to controlling for the endogeneity in the relationship.
\end{abstract}

*Corresponding author; Department of Economics and Centre for European Labour Market Research, University of Aberdeen, Edward Wright Building, Aberdeen AB24 3QY, Scotland, UK; phone: 44-(0)1224-273411; email: kabender@abdn.ac.uk

The authors are grateful to two referees of this journal for helpful comments. The usual caveat applies. 


\section{Introduction}

In Europe, flexible employment contacts have come to the forefront of the economic policy debate as the European Commission promoted the concept of 'flexicurity'. Although it is not clear that the pace of structural change has increased over time, the process of globalisation, increased European integration and technological development has provided a perception of a need for labour market flexibility enabling employers to respond to market pressures in order to respond to changing circumstances and to retain a competitive advantage in the face of global market pressures. Thus, the European Commission published in June 2007 a communication as a response to a call from the European Council (Presidency Conclusions 2006, 2007) to explore how to establish the conditions for "flexicurity" (European Commission 2007, p. 4). In order to be consistent with the goals of the Lisbon Strategy, the Commission argued that flexicurity could deliver increased employment opportunities while also being a vehicle to update European social policies. Thus, the Commission defined flexicurity as "an integrated strategy to enhance, at the same time, flexibility and security in the labour market" (p. 4).

Interestingly after this policy change, a large segment of the labour market now is exposed to more unstable forms of employment. One of the important unstable forms of employment is temporary employment with those individuals in temporary jobs facing far shorter job durations and greater job instability compared to those in full-time permanent jobs (Gregg and Wadsworth 1995, 1996). An important development is the trend towards 'zero-hour' contracts, which imply that workers are employed without any guarantee about the amount of time they will work. The Financial Times (April 7, 2013) reports that according to UK government estimates, $23 \%$ of employers now use zero-hour contracts. The total number of employees on zero-hours contracts rose 25 per cent over the course of 2012 and more than 150 per cent since the autumn of 2005 . Since 2005 , the yearly number of zero-hour contracts have increased from 50,000 to 200,000. A recent report by the UK University and College Union (2013) shows that two-thirds 
of universities in the UK use zero-hour contracts. In September 2016 the Office for National Statistics calculated that 903,000 individuals (2.9\% of the employed workforce) were on zerohours contracts - which do not offer guaranteed hours or sick leave.

Although increased labour market flexibility is allegedly expected to improve the employment and labour force participation rates, the shift to non-standard contracts and the deregulation of the institutional framework that traditionally supported vulnerable groups of the working population has been associated with lower income, greater job and financial insecurity and, thus, potentially a reduced quality of life. on the increased uncertainty of income and job security may have the unintended consequence of negatively impacting the health and psychological well-being of employees, and thus, policy makers may obtain a wider understanding of how to assess the total impact of socio-economic policies on individual wellbeing, informing the design of a welfare policy that looks at just more than standard economic outcomes (Frey and Stutzer, 2002).

The novelty of this paper is that it investigates the impact of the flexible employment contracts on workers' physical and mental health in Britain. It focuses on seasonal or temporary jobs or fixed time contracts that are the most common forms of atypical and flexible jobs. Survival analysis is used to estimate the hazard of a healthy worker having his or her health deteriorating as a result of the time spent in an atypical employment contract. Other things equal, it is shown that the longer the amount of time spent in atypical employment contracts increases the odds of falling into ill health for a variety of health conditions.

The present paper is structured as follows. Section 2 briefly reviews some of the existing studies examining the impact of flexible employment contracts on employee physical and psychological health. In Section 3 the survival analysis statistical technique to be used in the empirical analysis is outlined. Section 4 describes the data that has been generated for the purposes of this study. Section 5 contains a discussion of the empirical results and provide 
evidence for their robustness with respect to the endogeneity in the relationship between flexible employment contracts and employee physical and psychological health . Section 6 concludes.

\section{A Brief Literature Review}

In the $20^{\text {th }}$ Century, many firms relied on long-term and stable employer-employee relationships as a means of human resource management. Employers relied heavily on an 'invisible handshake' as opposed to the 'invisible hand' that cannot operate effectively in the labour market when employment contacts cannot perfectly foresee future contingencies (Okun, 1980). These ideas were formalised in the theoretical framework of the 'Implicit Contact' theory (e.g., Baily, 1974; Gordon, 1974; Azariadis, 1975; Azariadis and Stiglitz, 1983) which in its simplest form can be described as an employment contract over two states of nature; a good state when demand is high and the worker's marginal revenue product (MRP) is high and in adverse states, when demand is low and the value of the marginal revenue product is low. The main idea is that the individual worker is more risk averse than the individual employer, due to significant differences in wealth. In addition, employers and executives have greater experience in financial affairs and, thus, are more able to counter financial risks than an average employee. Hence, the worker has much lower ability to bear risks and values a wageemployment contract that reduces risk over the two states of nature. Thus, since workers dislike income uncertainty and dislike being jobless, firms find a profitable employment strategy to maximise profits, and to attract and retain workers, by providing a contact that reduces the risk to the worker over good and adverse states of the economy. This enables firms to attract and retain a high quality pool of workers, eliminate information asymmetries about their ability and productivity, foster specific training skills, while employees were likely to reciprocate to their employer's loyalty by exerting greater effort (Akerlof, 1982). 
Yet, recently these attitudes are increasingly seen as obsolete in the advanced economies, as the notion of a 'job for life' has ceased to exist. Current attitudes to human resource management and employment tend to shift the burden of the risk to the worker. The stability of the wage level over good and adverse states can be retained only via a corresponding variation of employment or, alternatively, any decrease in demand would be accompanied with variations in wages. Hence, currently there is a marked labour market trend towards an increase in the use of precarious or 'atypical' forms of employment and an increasing burden of risk on the workforce. These forms of employment include fixed term contracts, temporary or casual contracts, temporary-help agency work and the like.

However, as the risk has been transferred from the firm to worker, economists and policymakers have become increasingly interested in investigating the effects of precarious forms of employment on individuals' well-being, quality of life and health. A detailed review of the evidence is beyond the scope of this study, particularly given the broad reviews on the association between temporary employment and health status by Virtanen et al. (2005) and De Cuyper et al.(2008). Reviewing the available literature, these studies conclude that an association between temporary/flexible employment and psychological morbidity and that the health risk may depend on instability of temporary employment and the context. Economists have typically attempted to estimate the utility cost of moving towards such precarious modes of work. Thus, although they find evidence that fixed-term contracts function as effective stepping-stones towards permanent jobs, especially for women, Booth et al. (2002) show that temporary jobs in the UK are not desirable as a means of long-term careers. Such jobs typically pay less than corresponding permanent jobs and are associated with lower levels of job satisfaction and poorer work-related training, ceteris paribus. In addition to the abovementioned literature surveys, a comprehensive recent meta-analysis study (Sanwald and Theurl, 2015) provides summary evidence on the relationship between employment contracts 
and health using 52 studies covering 26 countries in the time period $1984-2010$. The study distinguishes between six types of employment contracts (fixed-term, temporary, casual, oncall, daily or no formal contract) and health outcomes (sickness absence, occupational injuries, health-related behaviour, mental health and physical health). The study shows that a higher risk of occupational injuries for atypical employees and that atypical employment increases the likelihood of mental and physical health.

The above results are corroborated by evidence from a number of epidemiological studies that show a close association between precarious types of employment and low psychological wellbeing or mental distress (e.g. Benavides et al., 2000; Aronsson et al. 2002; Virtanen et al. 2002; Waenerlund et al. 2011; Sirviö et al. 2012). Furthermore, Pouliakas and Theodossiou (2005) find that temporary, part-time workers in eleven European labour markets are strongly dissatisfied compared to those on permanent, full-time contracts. In a further study, they demonstrated (Pouliakas and Theodossiou, 2010) that other things equal the anticipated psychological 'costs' of moving from a riskless permanent contract to the insecurity of flexible employment or no work at all appear to be very significant.

However, De Cuyper et al. (2008) point out that some of the empirical evidence on health and psychological impact of precarious types of work suffers from a number of shortcomings stemming from the heterogeneity of precarious workforce (fixed-term, part-time, temporary, irregular, atypical, casual jobs, non-standard working etc.) and the inconsistent definitions of precarious type of work. Furthermore, results may be biased due to methodological limitations relating to non-random selection into flexible employment and the effects of confounding factors in regression models.

Although the previous literature identifies a linkage between (particularly psychological or subjective wellbeing) health and flexible contracts using either small scale surveys for specific groups or cross section survey data, to the knowledge of the authors, none has examined the 
potential link between precarious contracts and physical health over a long period of time using large scale survey data. While data limitations are a partial cause of the lack of research, there are strong reasons to expect that such a link is real and significant.

Rose and Marmot (1981), Bosma et al. (1997), Sapolsky (2005), Vitetta et al. (2005) and Wilkinson and Pickett (2006, 2009) offer wide and convincing epidemiological and medical evidence indicating that increased stress, and in particular, long-term 'low grade' stress, can lead to ill health. Importantly, the long term effects of employment uncertainty on individual functioning are clearly implied in Leombruni et al. (2013) since they find that workers exposed to the stress and uncertainty of job loss due to firm closure exhibit a large and significant risk of workplace injury after reemployment. By their nature atypical employment, namely fixedterm, part-time, temporary, irregular, atypical, casual jobs, non-standard working contracts, increase uncertainty about the future. This increased uncertainty explains at least some of the reduced job satisfaction and increased psychological stress shown by those in such flexible contracts. This is the first paper that examines this link between precarious employment and health.

\section{Econometric Methodology}

Because the medical linkage between stress and ill health is not instantaneous, time is a key element in the analysis. Hence, this study models the effects of precarious employment in a duration framework, to examine the effect of increases in the amount of time spent in atypical/temporary employment contracts on health. Initially the Cox (1972) hazard model approach is employed, a methodology that is frequently used in the duration models literature.

However, De Cruyper et al. (2008) discuss a number of issues regarding the potential problems of individual heterogeneity on estimating the effects of employment contract on health. This concern echoes Heckman and Borjas (1990) and Lancaster (1979) who have 
pointed out that unobservable heterogeneity (or frailty) can significantly bias the results in a hazard estimation framework. The frailty arises when unobserved personal characteristics or other relevant factors are not taken into account. As Vaupel et all (1979), Hanagal (2011) and Wienkle (2011) show the ability of frailty term to capture the unobservable random effects shared by individuals with similar (unmeasured) risks affecting the exit rates and Jenkins (2005) shows that a discrete mixture model can describe adequately the unobserved heterogeneity between individuals. This methodology allows for discreteness in periods of observation and, importantly, a nonparametric specification of individual heterogeneity or frailty. It is based on Jenkins (1995) and Stewart (1996), which is an adaptation of PrenticeGloeckler (1978) by Meyer (1990), and is briefly described below. In the regressions, the dependent variable is the dummy variable indicating if a spell of good health has been observed to end. Only continuous spells of good health are considered - once an individual exits the panel they are deemed to have left the panel for good: re-entry to the panel is not allowed.

Each individual is observed at a number of points in time. In the dataset, time intervals are of one year of length. The interval boundaries are also one year of length $t=1,2,3, \ldots$ and the interval $t$ is $(t-1, t]$. A spell of good health can either be complete $\left(c_{i}=1\right)$ or right censored $\left(c_{i}=0\right)$. A censored spell of good health $i$ with length $t$ intervals contributes to the likelihood function with the discrete time survivor function,

$$
S_{i}(t)=P\left(T_{i}>t\right)=\prod_{k=1}^{t}\left(1-h_{i k}\right)
$$

where $T_{i}=\min \left\{T_{i}^{*}, C_{i}^{*}\right\}, T_{i}^{*}$ is a latent failure time and $C_{i}^{*}$ a latent censoring time for spell $i$, and the discrete hazard is $h_{i k}=P\left(k-1<T_{i} \leq k \mid T_{i} \geq k-1\right)$. A complete spell $i$ in the $t$ th interval contributes to the likelihood with a discrete time density function, 


$$
P\left(t-1<T_{i}<t\right)=S(t-1)-S(t)=\frac{h_{i t}}{1-h_{i t}} \prod_{k=1}^{t}\left(1-h_{i k}\right)
$$

The log-likelihood is, therefore,

$$
\log L=\sum_{i=1}^{n} c_{i} \log \left(\frac{h_{i t}}{\left(1-h_{i t}\right)}\right)+\sum_{i=1}^{n} \sum_{k=1}^{t} \log \left(1-h_{i k}\right) .
$$

Jenkins $(1995,2005)$ shows that this can be reformulated as the log likelihood function of a binary dependent variable $y_{i k}$

$$
\log L=\sum_{i=1}^{n} \sum_{k=1}^{t}\left[y_{i k} \log h_{i k}+\left(1-y_{i k}\right) \log \left(1-h_{i k}\right)\right]
$$

where $y_{i k}=1$ if spell $i$ ends in year $t$ and $y_{i k}=0$ otherwise.

Furthermore, Prentice and Gloeckler (1978) show that the complementary log-log function

$$
\begin{aligned}
& c \log \log \left[1-h_{t}\left(X_{i t}\right)\right] \equiv \log \left(-\log \left[1-h_{t}\left(X_{i t}\right)\right]\right)=\beta_{0}+X_{i t} \beta+\gamma_{t} \\
& \Rightarrow h_{t}\left(X_{i t}\right)=1-\exp \left(-\exp \left(\beta_{0}+X_{i t} \beta+\gamma_{t}\right)\right)
\end{aligned}
$$

is the appropriate form for such grouped-interval data, where $\gamma_{t}$ is the interval baseline hazard and $X_{i t}$ are covariates that may be time-varying but are constant within intervals.

An approach to account for an arbitrary nonparametric distribution for individual heterogeneity is suggested by Heckman and Singer (1984). They assume that each individual belongs to one of a number of different types (mass points), $z=1, \ldots, z$, where membership of each type is unobserved. They, then, allow the intercept term in the hazard function to differ across the types. In view of this, the hazard becomes

$$
h_{t z}\left(\mathbf{X}_{i t}\right)=1-\exp \left[-\exp \left[m_{z}+\beta_{0}+X_{i t} \beta+\gamma_{t}\right]\right]
$$


where $m_{z}$ describes the nonparametric distribution of the individual heterogeneity component, and $m_{1}$ is normalised to zero. This approach is implemented in this paper by using the "hshaz" subroutine available in STATA (Jenkins, 2005).

The above subroutine estimates a log-log model. It converges to a proportional hazard model as the hazard rate tends to zero. In most applications the hazard rate is sufficiently small and hence the above model converges to

$$
\left|\frac{h_{t z}}{1-h_{t z}}\right|=\exp \left\{m_{z}+\beta_{0}+X_{i t} \beta+\gamma_{t}\right\}
$$

Hence, the exponentials of the estimated regression coefficients can be interpreted as odds ratios.

To retain some homogeneity in the sample, in line with studies such as Marmot et al., (1978a), Marmot et al., (1978b), Marmot et al., (1991) and Marmot and Davey (1997), the sample is restricted to individuals employed for the whole observation period so as factors such as unemployment and absolute poverty cannot affect the findings because everybody in the study is in paid employment (either in flexible or permanent contracts) for each year that they are in the sample.

The methodology adopted in this paper establishes the likely direction of causality purging by construction the possibility of endogeneity as much as possible. The sample is constructed to initially consist of workers who report having good or excellent health and are currently working at the start of the survey. Then workers are followed through the survey. If a worker experiences bad health (that is, exiting good health), his or her socioeconomic status is recorded. Otherwise, if the worker remains in good health throughout our time period, his or her socioeconomic status is recorded for the last period he or she is observed. Thus, because we only focus on those with good health initially, the procedure forces the direction of causality 
from paid employment (temporary or permanent contract) to health, since the individual who enjoys good health is first observed to exit good health on the account of the advancing share of the flexible or permanent paid employment, ceteris paribus.

In addition to this sample design, the econometric specification addresses with endogeneity in other ways as well. Frailty corrections in the duration analysis can control for inherent factors that might contribute to ill health and possibly the choice of taking nonpermanent jobs. Further specifications that estimate an augmented model introduces an explicit control for the past health of the individual in the main formulation. A final robustness check to control for any possible endogeneity happens when the sample is further restricted to individuals who are in good health and in permanent employment at the initial period so any move to temporary employment and to ill health takes place only within the observation period.

\section{The data}

The data for this study come from 17 waves of the British Household Panel Survey (BHPS), a nationally representative survey of British residents. In order to implement the strategy described above, healthy workers are selected and are followed until they either experience a worsening of their health condition or they are not observed anymore (and thereby, become censored observations). The total length of time in good health is recorded for each individual.

Several different health measures are employed in this study. Subjective health is derived by the information provided by the respondents regarding how their health has been over the past 12 months. Those who state that it was excellent or very good are classified as those who are healthy while other responses suggest ill health. Furthermore, the BHPS has a variety of other, more objective, health problems, namely heart or blood pressure problems; stomach or digestion problems; anxiety, depression and other psychological problems; breathing or chest problems; migraines; skin conditions and allergies; or 'other' health conditions. Workers are 
considered to be in good health if the specific health condition was not mentioned while ill health was specified when the condition was mentioned.

The key independent variable is the percentage of time spent in a flexible employment. For the first eight waves of the BHPS, respondents are asked to identify if their current job was permanent, seasonal/temporary job or a fixed time contract. For the remaining nine waves the respondents are asked to first identify whether their job is permanent or non-permanent and in a follow-up question to identify the kind of non-permanent job they do. This study combines the responses in two groups permanent and flexible employment contracts. ${ }^{1}$ A set of standard demographic variables - gender, education, race, splines of age, marital status, region, and current smoking status - are also included in the regressions as control variables. However, it should be noted that this study takes into to account any unobserved heterogeneity (omitted factors/variables) through an arbitrary nonparametric distribution of individual heterogeneity.

\section{Empirical Results}

\subsection{Survival Plots}

Before turning to the regression results, the Kaplan-Meier non parametric survival plots are shown in Figures 1-8 for the subjective and objective health measures. In these figures, a dummy variable is used to indicate when a worker has been in flexible employment for at least 50 percent of the time that they are observed. Figure 1 indicates the survival plots for the subjective health measure, with the dotted line as the survival plot for those in flexible employment for more than 50 per cent of the time. As can be seen, the survival plot drops much more quickly for the group who have long exposure to flexible contracts. Indeed, as seen

\footnotetext{
1 This includes the self-employed who also answer this question on whether their job is permanent or temporary. Registered disabled are excluded from the sample in order to preserve some homogeneity of the sample.
} 
in Figures 2-8, the hazard of falling out of good health is much higher for those with long exposure to flexible employment contracts for the entire range of objective health measures.

\subsection{Hazard Regressions}

Of course in the above figures there are no controls for any confounding factors. Thus, in this section, the results from a series of hazard regressions are discussed to identify the correlation between flexicurity provisions such as flexible employment contracts on health. Table 1 contains the results of three sets of regressions for subjective health. The first column reports the results from a standard Cox hazard model. The key variable of interest is the percentage of time spent in flexible employment. ${ }^{2}$ The results for this variable are found in the first row and indicate that an increase in the time spent in flexible employment increases the odds of going into bad health, relative to time spent in a permanent job. Although the point estimate is small, it is important to note that this is for a one percentage point increase in the amount of time spent in flexible employment. To get a better idea of the magnitude of the effect, if one increases the time spent in flexible employment by one standard deviation (about 14.6 percentage points), it would increase the odds of falling into bad health by 1.091 . To gain some perspective of the size of this impact, one can compare this effect to the effect of smoking on health. Thus, for a one standard deviation increase in the time spent in a temporary job, the negative health consequence for subjective health is about $42.1 \%$ for the Cox regression of that of smoking - a relatively large effect.

The second and third columns of Table 1 exhibit results using the Prentice-Gloeckler method as modelled by Jenkins. The second column allows for discrete time periods.

\footnotetext{
${ }^{2}$ The other covariates generally confirm intuitive relationships between the variables and ill health. Compared to white workers, non-white workers are more likely to fall into bad health. Married workers are somewhat more likely to fall into ill health, as are workers in London (compared to other parts of England). There is little effect of education, except for higher odds from those without secondary schooling degrees. As expected a decrease in household income increase the hazard of falling into bad health. Smoking has a similar effect.
} 
However, allowing for discreteness does not diminish the statistical significance of the effect of flexible employment contract - indeed the point estimate is slightly larger than in the Cox regression. When the effects of unobserved heterogeneity (frailty) are taken into account in the last column the odds ratio now increases to 1.013 (or 1.208 for a one standard deviation increase in the per cent of time in flexible employment - equivalent to $42.9 \%$ of the effect of smoking on health) ${ }^{3}$.

Table 2 reports a set of odds ratios for different hazard regressions for each of the objective health measures. Each cell in the table represents selected results from a different regression, but all are the odds ratio of increasing the percentage of time spent on a flexible contract. While the point estimates of the increase in the odds ratio does differ slightly across illness measure and regression methodology, the results are remarkably consistent. All odds ratios are significant at the five per cent level (at least) and all fall into the range of 1.008 to 1.018 for a one percentage point increase in time spent in flexible jobs relative to permanent jobs (or 1.123 to 1.286 increase for a one standard deviation change). As with subjective health, the results are also robust with respect to hazard estimation methodology, with the point estimates increasing even when frailty is controlled for. Thus, this implies robust and consistent evidence that continued exposure to the stress of flexible employment increases the risk of bad health. ${ }^{4}$

\subsection{Subsamples}

\footnotetext{
${ }^{3}$ Putting the other health categories in relation to smoking using the Cox (frailty corrected) results, the respective figures for the heart health is $92.5 \%(48.7 \%)$, for stomach health $41.9 \%$ (31.2\%), anxiety/depression $35.0 \%$ $(33.3 \%)$, breathing $18.6 \%$ (15.6\%), migraine $184.5 \%$ (155.7\%), skin $79.4 \%$ (30.8\%) and for other health problems $42.3 \%(50.6 \%)$.

4 To investigate the possible nonlinearities in the effect, a squared term of time in flexible employment or splines at thirds were introduced in the regression. The squared term turned out to be insignificant and the spline terms showed that after a no harmful health effect for very short time of exposure to flexible employment, there is a sustained and significant harmful effect for higher levels of exposure consistent with the linear specification. Results are available from the authors.
} 
Although the results above are indicative of the full sample, two further sets of regressions are estimated to evaluate if these results are consistent across subgroups in the population. First, separate regressions for males and females are estimated, in view of the evidence that health and employment patterns are different across genders. Second, it may be that there are compensating differentials paid for the uncertainty of flexible employment (at least at the hourly level). Since previous research shows that health increases with income, one would expect that under compensating differentials, the increased income would mitigate the effects of flexible employment on health.

The results of this exercise are found in Table 3. There are some interesting differences across illnesses and samples. For example for subjective health, while both males and females experience higher odds of falling into ill health with an increase in the percent of time in flexible employment, the effect seems to be larger for males. Likewise, rather than mitigating the detrimental effects of flexible employment on health, the odds of ill health are much higher for those whose household income is above the median. ${ }^{5}$

Looking at the objective measures of health, this pattern of larger effects for males in both heart and breathing illness is found. There seems to be little difference between genders for stomach health and skin allergies, while flexible work affects women more for anxiety/depression, migraines and 'other' health conditions. The odds of ill health are much higher for those whose household income is above the median in the case of heart, stomach, and breathing, while the 'other' health conditions are more prevalent among poorer workers.

Overall, the above results confirm that although there is some heterogeneity across different subsamples, the longer exposure to flexible employment contracts is correlated with ill health.

\footnotetext{
${ }^{5}$ However, the results of this should be viewed with caution since household income is used rather than earned income. So any compensating differential effects may be mitigated because of the income of the other members of the household.
} 


\subsection{Robustness Checks}

In this section a number of specifications are used to evaluate the robustness of the results:

\subsubsection{Sample Sensitivity}

A potential issue that may arise concerns the selectivity of the results to the construction of the sample. As discussed above, the sample consists of people who are in good health in the first wave of the BHPS and then followed until they either fall into bad health or drop out of the sample (i.e. the censored group). Once this sample is set, then the percentage of time spent in permanent or flexible jobs is calculated. However, for those in the sample for only a few waves, these percentages are quite discrete with little variation. To evaluate the sensitivity of the results to these possible influential observations the regressions are re-estimated including in the sample only those who are observed for at least five waves. Results from this exercise are found in Table 4. Except for the cases of heart and anxiety/depression health, the results are still statistically significant, and indeed, the statistically significant odds ratios are generally larger once the sample is restricted to those in the sample the longest times.

The second robustness check relates to the sample homogeneity. The results reported above are based on a sample in line with the literature (e.g. the 'Whitehall' studies of Marmot and others cited above), which shows that it is desirable to focus on a sample of individuals who are always in employment. This provides a homogeneous group of individuals who have continual exposure to work and so factors such as unemployment and absolute poverty cannot affect the findings because all those included in the study are in paid employment, throughout the period of observation. Nevertheless, those on flexible contracts are likely to spend some time in non-employment. Thus, the sample is expanded to allow for individuals who may be out of work, either due to unemployment or being out of the labour force (although each individual spends at least one wave in a flexible or permanent job so all individuals have had 
the opportunity to experience an employment spell). Table 5 shows the results from this estimation. In general, expanding the sample to allow for different labour market statuses confirms the main conclusion of this study, namely an increase in the percentage of time in flexible contracts relative to the percentage of time spent in a permanent job increases the odds of falling into ill health. ${ }^{6}$ This is consistent across all heath types except for heart and 'other' illnesses which, while positive, are now statistically insignificant.

\subsubsection{Endogeneity Issues}

An issue of importance in estimating the effects of employment contracts on health is the issue of endogeneity. The methodology adopted in this paper purges by construction the possibility of endogeneity associated with causality as the sample initially consists of workers who report having good or excellent health and are currently working at the start of the survey. However, some residual endogeneity may remain which mainly may be associated with inherent factors that might contribute to ill health and possibly the choice of taking nonpermanent jobs. Thus individuals with uncertain or weak health may exhibit weak attachment to the labour market thus preferring short-term, temporary or seasonal employment contracts. In this study such forms of endogeneity are likely controlled by the frailty corrections capturing such inherent factors that might contribute to ill health and possibly the choice of taking nonpermanent jobs.

\footnotetext{
${ }^{6}$ One issue that might arise is that the specific structure of the BHPS does not provide information about the employment experiences of the individual within the year but only at the time of the survey, once per year. Thus if the individual has experienced unemployment during the year, this may cause anxiety and stress which may be harmful to health but this is not controlled in the regression. Typically, such unobserved heterogeneity is expected to be captured by the frailty correction and should be mitigated. However, to further investigate this issue, the models are re-estimated after excluding all those who have experienced some unemployment during the year, since there is information in the BHPS on whether the individual has experienced unemployment during the preceding year. In view of the fact that the study by design includes only individuals who are working in every wave only $3 \%$ of the sample are in this category. The results of this exercise reveal no significant change from the results reported above and are available upon request. The authors thank an anonymous referee of this Journal from pointing out this issue.
} 
However, to further investigate the effects of endogeneity on the estimated results, an augmented model is re-estimated by introducing a control for the past health of the individual in the main formulation. In doing so, this robustness check uses a sample of the BHPS from Wave 5 onwards. Thus, healthy workers are identified in Wave 5 and followed through until they experience a spell of bad health or are censored. Health information from Waves 1 to 4 are utilised to identify if the worker had experienced any bad spell of health in this period. If there is a spell of bad health an additional dummy variable to indicate this spell is created.

Table 6 contains the results from this robustness check. In the Table, for reference the 'All Waves' row repeats the results from Table 1 or Table 2 (for the respective illness). The row with 'Last 13 Waves' contains the odds ratio for the percent of time spent in a flexible contract, but without any control for past health. By comparing these two rows one is able to assess if there is any substantive difference in the coefficients when the panel starts in Wave 1 ('All Waves') or starts in Wave 5 ('Last 13 Waves'). In general, it turns out that there is very little difference. If anything the odds ratios tend to be somewhat higher for the latter sample, and all are statistically significant and indicate higher hazards. The final row for each health outcome includes the past ill health dummy variable. In general, the odds ratios decrease by a small amount but remain statistically significant in all regressions. Thus, the results from earlier are robust to the inclusion of this variable with the odds ratios little changed from the 'Last 13 Waves' row.

In view of the importance of the issue of endogeneity a further robustness check is employed since one could argue that approaching ill health that has not yet manifested itself may be associated with the likelihood of someone being observed in temporary rather than permanent contract in the initial period. One way to investigate this is to restrict the sample at the initial period to include individuals who are in good health and in permanent employment. Thus any moves to temporary employment are observed within the observation period. In this 
case one should expect that the direction of causality is clearly from paid employment to health. The individual enjoys good health in permanent employment at the start and he or she is observed to exit good health on the account of the advancing share of the flexible or permanent paid employment within the observation period, ceteris paribus. However, in performing this set up it was found that the number of observations of workers who experience employment in a temporary contract falls dramatically (to between 40 to 60 individuals depending on the measure of health). In view of this, any multivariate regression estimates are not estimated with much precision. Hence, only non-parametric Kaplan-Meier plots for each of the health measures are presented in Figure 9. The hazards consistently demonstrate that the risk of health deterioration is higher for those with high percentages of temporary/flexible contract experience even though at the initial period they were employed in a permanent contract. Although, the above results constitute a tentative illustration of the insignificant effect of the endogeneity they are salutary since along with the corrections of the frailty heterogeneity and the initial selection of workers in good health, these survival plots suggest that the problem of endogeneity may not be important in the context of his paper. ${ }^{7}$

\section{Pathway}

Although the results reported in this study show that the use of flexible contracts increase the incidence of ill health, it would be useful to know the pathway of this outcome. It is not likely that there is a direct and immediate link between the onset of a flexible contract to heart

\footnotetext{
7 As mentioned above a further pathway for endogeneity to affect the estimated results is through individual unobserved health behaviours. For instance, individuals with precarious working experience may attach low importance to health thus taking more health risks, e.g. by smoking. As it is explained above these unobserved factors are taken into account by the frailty correction. Nevertheless, to investigate further the issue the nonsmoker group in the sample was selected and the model was re-estimated. The results showed that the effect of flexible employment on health of non-smokers was significantly detrimental with the point estimates often larger than the results for the mixed group. The authors thank an ammoniums referee of this journal for pointing this out. The results of this exercise are available from the authors on request.
} 
problems, for example. However, as suggested above, the linkage may be through the increased stress suffered by the worker as he or she bears the risk of precarious employment contracts. While the BHPS does not contain any biomarkers that would medically indicate stress, there are a series of questions from the General Health Questionnaire (GHQ) that do involve stress - problems with sleep, problems with decision making, feeling under strain, problems overcoming difficulties, loss of confidence and loss of happiness. Using the same methodology as above with the health indicators, each of these problems is investigated in turn - starting with a sample of workers who do not express the stress indicator. They are followed over time until they signal a problem with that stress measure or are censored. The same set of regressors are included in the regression as before, including the key variable of the percent of time spent in flexible contracts.

Table 7 reports the results from these regressions with the odds ratios on the percent of time in flexible contracts for the three sets of duration models and for the various samples examined earlier. In each of the full sample regressions, there are higher odds of having stress as the percent of time in flexible employment increases, all in the 1.004 to 1.015 range, indicating that an increase in time in flexible employment is correlated with higher stress levels as measured by loss of sleep, difficulty in decision making, etc. As above, the frailty corrected models have the largest point estimates of the odds ratios.

As with the health measures, there is more heterogeneity among the samples. The effect of flexible employment on sleep and problems overcoming difficulties affect women more than men, while men on flexible contracts are more likely to have problems decision making or lose confidence. Except for sleep problems, the odds ratios are significant for both income groups and tend to be higher for the more highly paid. In general, the central point is that the increased exposure to forms of atypical contracts such as those used in this paper causes higher odds of feeling stress for nearly all subsamples. Notwithstanding the robustness of these results one 
would expect that they are only suggestive of the pathway. For more precise investigation of these issues, appropriate data are needed concerning measurement of stress (e.g. better measures of direct stress such as biomarkers of physical stress) or impacts on health behaviours (e.g. exercise, drinking, smoking, relaxation, etc.). Better data will, therefore, facilitate the identification of the pathway and may give areas where public health policies could address the problems of atypical employment.

\section{Conclusions}

Flexible employment contracts are thought to offer flexibility in the labour market and promote higher employment levels. However, flexible employment contracts are inherently insecure since precarious employment induces uncertainty and hence stress among the affected workers. This study examines the impact of flexible employment contracts (specifically seasonal or temporary job or a fixed time contracts) on workers' psychical health. Survival analysis is used to estimate the hazard of a healthy worker having his or her health deteriorating as a result of the time spent in some form of atypical or flexible employment contract. Other things equal, it is shown that the longer the amount of time spent in flexible employment contracts increases the odds of falling into ill health for a variety of health conditions. The results are robust to variations of the sample, endogeneity and to controlling for the effect of past health.

Precarious employment contracts are associated with higher risk and less control one has over his/her own life and income as well as the level of participation in the society. Individuals with long spells of 'atypical' or precarious employment have higher levels of stress due to their inability to control their lives. Indeed this study shows that such contacts are associated with a higher hazard of exhibiting high levels of stress indicators. In short, flexible employment contacts have severe negative externalities and, as the empirical literature shows, very 
uncertain employment or labour market career has become commonplace for a growing part of the workforce.

However, notwithstanding the evidence provided by this paper, it would be useful to further extend this research. For example, there are many different types of flexible contracts, and it would be interesting to see if the results found above are replicated for these different types of contracts. Furthermore, the pathways through which the uncertainty generated by the flexible contracts affects health should be investigated. In particular, there is a lack of good quality data to examine the effects of health behaviours such as drinking, exercise and the like. Although the BHPS has information on atypical contracts (specifically seasonal or temporary job or a fixed time contracts) and health, the data on health behaviours are available only for a subset of years, which makes it unsuitable for the panel estimation used in this study. Matching employment contract information to long-term panel data on health would give researchers the ability to delve into some of open questions in this research. Furthermore, datasets with biomarkers of stress would be helpful in identifying the medical pathway of stress that is induced by the uncertainty of flexible contracts.

\section{Compliance with Ethical Standards:}

Conflict of Interest: The authors declare that they have no conflict of interest. 


\section{References}

Akerlof, G.A. (1982), 'Labour contracts as partial gift exchange', Quarterly Journal of Economics, Vol. 97, pp. 543-69.

Aronsson G., Gustafsson, K. and Dallner, M. (2002), 'Work environment and health in different types of temporary jobs', European Journal of Work Organisational Psychology, Vol. 11, pp. 151-75.

Azariadis C. (1975) 'Implicit Contracts and Underemployment Equilibria', Journal of Political Economy, 83, 1183-201.

Azariadis C. Stiglitz J (1983) 'Implicit Contracts and Fixed Wage Equilibria', Quarterly Journal of Economics, 98, 1-22.

Baily, M. N. (1974), 'Wages and Unemployment under Uncertain Demand', Review of Economic Studies, 41, 37-50.

Benavides, F., Benach, J., Diez-Roux, A. and Roman, C. (2000), 'How do types of employment relate to health indicators? Findings from the Second European Survey on Working Conditions', Journal of Epidemiology and Community Health, Vol. 54, pp. 494-501.

Booth, A. L., Francesconi, M. and Frank, J. (2002), 'Temporary jobs: Stepping stones or dead ends?' The Economic Journal, Vol. 112, pp. F189-213.

Bosma, H., Marmot, M. G., Hemingway, H., Nicholson, A. C., Brunner, E. and Stansfeld, S. A. (1997), 'Low job control and risk of coronary heart disease in Whitehall II (prospective cohort) study’, British Medical Journal (Clinical Research Ed.), Vol. 314(7080), pp.55865.

De Cuyper, N., De Jong, J., De Witte, H., Isaksson, K., Rigotti, T. and Schalk, R. (2008), 'Literature review of theory and research on the psychological impact of temporary employment: towards a conceptual model', International Journal of Management Reviews, Vol. 10(1), pp. 25-51.

European Commission (2007) Towards Common Principles of Flexicurity: More and better jobs through flexibility and security, $\operatorname{COM}(2007) 359$ final.

Frey, B. and Stutzer, A. (2002), 'What can Economists learn from Happiness Research?', Journal of Economic Literature, 40(2): 402-435.

Gordon, D. F. (1974) 'A NeoClassical Theory of Keynesian Unemployment', Economic Inquiry, 12, 431-59.

Gregg, P. and Wadsworth, J. (1995), 'A short history of labour turnover, job tenure, and job security, 1975-93', Oxford Review of Economic Policy, Vol. 11, pp. 73-90.

Gregg, P. and Wadsworth, J. (1996), 'Mind the gap, please? The changing nature of entry jobs in Britain', Centre of Economic Performance, LSE Discussion Paper 303.

Hanagal D. D (2011), Modelling survival data using frailty models, CRC Press, London.

Heckman, J. J. and Borjas, G. (1990), 'Does unemployment cause future unemployment? Definitions, questions and answers from a continuous time model of heterogeneity and state dependence', Economica, Vol. 47, pp. 247-83.

Heckman, J. J. and Singer, B. (1984), 'A method for minimising the impact of distributional assumptions in econometric models for duration data', Econometrica, Vol. 52, pp. 271320.

Jenkins, S. (1995), 'Easy estimation methods for discrete-time duration models', Oxford Bulletin of Economics and Statistics, Vol. 57(1), pp. 129-38.

Jenkins, S. (2005), 'Discrete time (grouped data) proportional hazard models', http:// http://fmwww.bc.edu/repec/bocode/h/hshaz.html.

Kuuchler, H. (2013) 'Zero hours' contracts numbers leap', The Financial Times, London, 7 April. 
Lancaster, T. (1990), The Econometric Analysis of Transition Data. Cambridge University Press: Cambridge.

Leombruni, R., Razzolini T., Serti, F. (2013) The pecuniary and non-pecuniary costs of job displacement -The risky job of being back to work. European Economic Review, vol. 61, pp 205-216.

Marmot, M. G. and Davey, S. (1997), Socio-economic differential in health: the contribution of the Whitehall studies. Journal of Health Psychology 2(3), 283-296

Marmot, M. G., Adelstein, A. M., Robinson, N. and Rose, G. A. (1978a), 'Changing social class distribution of heart disease', British Medical Journal, Vol. 2(6145), pp. 1109-12.

Marmot, M. G., Rose, G., Shipley, M. and Hamilton, P. J. (1978b), 'Employment grade and coronary heart-disease in British civil servants', Journal of Epidemiology and Community Health, Vol. 32(4), pp. 244-49.

Marmot, M., Davey Smith, G., Stansfeld, S., Patel, C., North, F., Head, J., White, I., Brunner, E. and Feeney, A. (1991), 'Health inequalities among British civil servants: The Whitehall II study', Lancet, Vol. 337: 1387-93.

Meyer, B.D. (1990), 'Unemployment insurance and unemployment spells', Econometrica, Vol. 58(4), pp. 757-82.

Okun, M. A. (1980), Prices and Quantities; A macroeconomic Analysis, Blackwell.

Pouliakas, K. and Theodossiou, I. (2005), 'Socio-economic differences in the perceived quality of high and low-paid jobs in Europe', Labor and Demography.

Pouliakas, K. and Theodossiou, I. (2010), 'Measuring the utility cost of temporary employment contracts using a conjoint analysis approach', Economica, Vol. 77, pp. 688-709.

Prentice, R. and Gloeckler, L. (1978), 'Regression analysis of grouped survival data with application to breast cancer data', Biometrics, Vol. 34, pp. 57-67.

Rose, G. and Marmot, M. G. (1981), 'Social class and coronary heart disease', British Medical Journal, Vol. 45, pp. 13-19.

Sapolsky, R. (2005), 'Sick of poverty', Scientific American, Vol. 293, pp. 92-9.

Sanwald, A. and Theurl, E. (2015), 'Atypical employment and health: A meta-analysis', Working Papers in Economics and Statistics, 2014-15, Faculty of Economics and Statistics, University of Innsbruck.

Sirviö, A., Ek, E., Jokelainen, J., Koiranen, M., Järvikoski, T. and Taanila, A. (2012), 'Precariousness and discontinuous work history in association with health', Scandinavian Journal Public Health, Vol. 40, pp. 360-67.

Stewart, M.B. (1996), "Heterogeneity specification in unemployment duration models', Unpublished paper, Department of Economics, University of Warwick, Coventry, UK.

University and College Union (UCU), (2013), 'Over half of universities and colleges use lecturers on zero-hour contracts,' http://www.ucu.org.uk/6749, accessed 15 Sept 2013.

Vaupel J. W, Manton K, G. and Stallard E. (1979). 'The impact of heterogeneity on individual frailty on the dynamic of mortality', Demography, 16(3), 439-54.

Virtanen, M., Kivimäki, M., Joensuu, M., Virtanen, P., Elovainio, M. and Vahtera, J. (2005), 'Temporary employment and health: a review', International Journal of Epidemiology, Vol. 34, pp. 610-22.

Virtanen, P., Vahtera, J., Kivimäki, M., Pentti, P. and Ferrie, J. (2002), 'Employment security and health', Journal of Epidemiology and Community Health, Vol. 56, pp. 569-74.

Vitetta, L., Anton, B., Cortizo, F. and Sali, A. (2005), 'Mind-body medicine: stress and its impact on overall health and longevity', Annals of New York Academy of Science, Vol. 1057, pp. 492-505. 
Waenerlund, A-K., Virtanen, P. and Hammarström, A. (2011), 'Is temporary employment related to health status? Analysis of the Northern Swedish Cohort', Scandinavian Journal of Public Health, Vol. 39, pp. 533-9.

Wienkle A. (2011) Frailty models in survival analysis, CRC Press, London.

Wilkinson, R.G. and Pickett, K.E. (2006), 'Income inequality and health: A review and explanation of the evidence', Social Science and Medicine, Vol. 62, pp. 1768-84.

Wilkinson, R.G. and Pickett K.E. (2009), 'The Spirit Level: Why equality is better for everyone', Penguin London. 
Table 1. Subjective Health Hazard Models

\begin{tabular}{|c|c|c|c|}
\hline \multirow[b]{2}{*}{ Variable } & \multirow[b]{2}{*}{ Cox } & \multicolumn{2}{|c|}{ Prentice-Gloeckler (hshaz) } \\
\hline & & without frailty & with frailty \\
\hline \multirow[t]{2}{*}{$\%$ time in flexible employment } & $1.006 * * *$ & $1.008 * * *$ & $1.013 * * *$ \\
\hline & (3.59) & $(4.20)$ & $(4.55)$ \\
\hline \multirow[t]{2}{*}{ Male } & 0.956 & 0.949 & 0.952 \\
\hline & $(-0.77)$ & $(-0.90)$ & $(-0.56)$ \\
\hline \multirow[t]{2}{*}{ Nonwhite race } & $1.406^{* *}$ & $1.503 * * *$ & 1.486 \\
\hline & $(2.27)$ & $(2.70)$ & $(1.56)$ \\
\hline \multirow[t]{2}{*}{ Age $15-25$} & $4.477 * * *$ & $6.276 * * *$ & $9.430 * * *$ \\
\hline & $(11.74)$ & $(14.13)$ & $(10.41)$ \\
\hline \multirow[t]{2}{*}{ Age $26-35$} & $3.133 * * *$ & $4.067 * * *$ & $7.173 * * *$ \\
\hline & $(11.85)$ & $(14.49)$ & $(13.01)$ \\
\hline \multirow[t]{2}{*}{ Age $36-45$} & $1.896 * * *$ & $2.164 * * *$ & $2.873 * * *$ \\
\hline & $(7.22)$ & $(8.70)$ & $(7.71)$ \\
\hline \multirow[t]{2}{*}{ Age $46-55$} & $1.441 * * *$ & $1.546 * * *$ & $1.799 * * *$ \\
\hline & $(4.17)$ & $(4.97)$ & $(4.34)$ \\
\hline \multirow[t]{2}{*}{ Married } & 1.113 & $1.150 * *$ & $1.231 * *$ \\
\hline & $(1.58)$ & $(2.05)$ & $(2.05)$ \\
\hline \multirow[t]{2}{*}{ London } & $1.210 * *$ & $1.276 * *$ & $1.466 * *$ \\
\hline & $(2.03)$ & $(2.59)$ & $(2.36)$ \\
\hline \multirow{2}{*}{ Wales } & 0.940 & 0.927 & 0.996 \\
\hline & $(-0.53)$ & $(-0.66)$ & $(-0.03)$ \\
\hline \multirow{2}{*}{ Scotland } & 1.103 & 1.138 & 1.086 \\
\hline & $(1.06)$ & $(1.40)$ & $(0.54)$ \\
\hline \multirow[t]{2}{*}{ University degree } & 0.868 & 0.858 & 0.958 \\
\hline & $(-0.79)$ & $(-0.85)$ & $(-0.15)$ \\
\hline \multirow[t]{2}{*}{ Secondary sch. degree } & 0.843 & 0.816 & 0.913 \\
\hline & $(-0.98)$ & $(-1.17)$ & $(-0.33)$ \\
\hline \multirow[t]{2}{*}{ No secondary sch. degree } & $1.394 *$ & $1.483 * *$ & $2.330 * * *$ \\
\hline & $(1.84)$ & $(2.18)$ & $(2.94)$ \\
\hline \multirow[t]{2}{*}{$\mathrm{HH}$ income in $1^{\text {st }}$ quartile } & $2.200 * * *$ & $2.566 * * *$ & $4.194 * * *$ \\
\hline & $(8.46)$ & $(10.04)$ & $(9.82)$ \\
\hline \multirow[t]{2}{*}{$\mathrm{HH}$ income in $2^{\text {nd }}$ quartile } & $1.746 * * *$ & $1.950 * * *$ & $2.726 * * *$ \\
\hline & $(6.55)$ & $(7.84)$ & $(7.62)$ \\
\hline \multirow[t]{2}{*}{$\mathrm{HH}$ income in $3^{\text {rd }}$ quartile } & $1.374 * * *$ & $1.441 * * *$ & $1.885 * * *$ \\
\hline & (3.89) & $(4.45)$ & $(5.05)$ \\
\hline \multirow[t]{2}{*}{ Current smoker } & $1.216 * * *$ & $1.279 * * *$ & $1.485 * * *$ \\
\hline & (3.19) & $(4.00)$ & $(4.09)$ \\
\hline \multirow[t]{2}{*}{$\ln ($ time $)$} & NA & $1.489 * * *$ & $3.678 * * *$ \\
\hline & & $(11.26)$ & $(16.24)$ \\
\hline
\end{tabular}

Notes: Numbers in parentheses are asymptotic z-statistics. All coefficients have been converted to odds ratios. *, **, and $* * *$ indicate $10 \%, 5 \%$, and $1 \%$ significance, respectively. The excluded variables are age greater than 55, non London England, postgraduate degree and the top quartile of household income. 
Table 2. Odds Ratios on Percent of Time Spent on a Flexible Contract Hazard Regressions for the Objective Health Measures

\begin{tabular}{lccc} 
& & \multicolumn{2}{c}{ Prentice-Gloeckler (hshaz) } \\
Sample & Cox & without frailty & with frailty \\
\hline Heart Health & $1.008^{* *}$ & $1.008^{* *}$ & $1.011^{* *}$ \\
& $(2.02)$ & $(2.16)$ & $(1.96)$ \\
Stomach Health & $1.012^{* * *}$ & $1.013^{* * *}$ & $1.018^{* * *}$ \\
& $(3.96)$ & $(4.24)$ & $(4.05)$ \\
Anxiety/Depression Health & $1.010^{* * *}$ & $1.010^{* * *}$ & $1.014^{* * *}$ \\
& $(3.05)$ & $(3.32)$ & $(3.11)$ \\
Breathing Health & $1.008^{* *}$ & $1.009^{* * *}$ & $1.010^{* *}$ \\
Migraine Health & $(2.52)$ & $(2.63)$ & $(2.35)$ \\
& $1.008^{* * *}$ & $1.009 * * *$ & $1.009^{* * *}$ \\
Skin/Allergy Health & $(2.84)$ & $(3.21)$ & $(3.21)$ \\
& $1.009^{* * *}$ & $1.010^{* * *}$ & $1.018^{* * *}$ \\
'Other' Health Conditions & $(3.24)$ & $(3.58)$ & $(4.12)$ \\
& $1.008^{* * *}$ & $1.009 * * *$ & $1.015^{* * *}$ \\
\hline
\end{tabular}

Notes: Numbers in parentheses are asymptotic z-statistics. All coefficients have been converted to odds ratios. $* *$ and $* * *$ indicate $5 \%$ and $1 \%$ significance, respectively. All regressions include the covariates in Table 1. 
Table 3. Odds Ratios on Percent of Time Spent on a Flexible Contract Hazard Regressions for the Objective Health Measures by Subsample

\begin{tabular}{|c|c|c|c|}
\hline \multirow[b]{2}{*}{ Health Illness and Sample } & \multirow[b]{2}{*}{ Cox } & \multicolumn{2}{|c|}{ Prentice-Gloeckler (hshaz) } \\
\hline & & without frailty & with frailty \\
\hline \multicolumn{4}{|l|}{ Subjective Health } \\
\hline \multirow[t]{2}{*}{ Female } & $1.005^{*}$ & $1.006 * *$ & $1.010 * * *$ \\
\hline & (1.94) & $(2.32)$ & $(3.01)$ \\
\hline \multirow[t]{2}{*}{ Male } & $1.008 * * *$ & $1.010 * * *$ & $1.016 * * *$ \\
\hline & $(3.00)$ & $(3.45)$ & $(3.56)$ \\
\hline \multirow[t]{2}{*}{ Income below median } & $1.005^{* *}$ & $1.007 * * *$ & $1.010 * * *$ \\
\hline & $(2.55)$ & $(3.25)$ & $(2.71)$ \\
\hline \multirow[t]{2}{*}{ Income above median } & $1.012 * * *$ & $1.015^{* * *}$ & $1.030 * * *$ \\
\hline & $(3.58)$ & $(4.06)$ & $(4.26)$ \\
\hline \multicolumn{4}{|l|}{ Heart Health } \\
\hline \multirow[t]{2}{*}{ Female } & 1.004 & 1.004 & 1.002 \\
\hline & $(0.67)$ & $(0.73)$ & $(0.25)$ \\
\hline \multirow[t]{2}{*}{ Male } & $1.012 * *$ & $1.013 * *$ & $1.022 * * *$ \\
\hline & $(2.34)$ & $(2.50)$ & $(2.96)$ \\
\hline \multirow[t]{2}{*}{ Income below median } & 1.004 & 1.005 & 1.008 \\
\hline & $(0.98)$ & $(1.13)$ & $(1.36)$ \\
\hline \multirow[t]{2}{*}{ Income above median } & $1.019 * *$ & $1.020 * * *$ & $1.040 * * *$ \\
\hline & $(2.52)$ & $(2.59)$ & $(3.46)$ \\
\hline \multicolumn{4}{|l|}{ Stomach Health } \\
\hline \multirow[t]{2}{*}{ Female } & $1.013 * * *$ & $1.014 * * *$ & $1.020 * * *$ \\
\hline & $(3.37)$ & $(3.62)$ & $(3.84)$ \\
\hline \multirow[t]{2}{*}{ Male } & $1.011^{* *}$ & $1.012 * *$ & $1.016^{*}$ \\
\hline & $(1.98)$ & (2.19) & $(1.93)$ \\
\hline \multirow[t]{2}{*}{ Income below median } & $1.010 * * *$ & $1.011 * * *$ & $1.023 * * *$ \\
\hline & $(2.90)$ & $(3.08)$ & $(4.23)$ \\
\hline \multirow[t]{2}{*}{ Income above median } & $1.017 * * *$ & $1.018 * * *$ & $1.033 * * *$ \\
\hline & $(2.66)$ & $(2.81)$ & $(4.47)$ \\
\hline \multicolumn{4}{|l|}{ Anxiety/Depression Health } \\
\hline \multirow[t]{2}{*}{ Female } & $1.011 * * *$ & $1.012 * * *$ & $1.016^{* * *}$ \\
\hline & $(3.00)$ & $(3.34)$ & $(3.02)$ \\
\hline \multirow[t]{2}{*}{ Male } & 1.006 & 1.006 & $1.018^{*}$ \\
\hline & $(0.89)$ & $(0.89)$ & $(1.90)$ \\
\hline \multirow[t]{2}{*}{ Income below median } & $1.010 * * *$ & $1.012 * * *$ & $1.021 * * *$ \\
\hline & $(3.13)$ & $(3.50)$ & $(3.68)$ \\
\hline \multirow[t]{2}{*}{ Income above median } & 1.005 & 1.006 & 1.002 \\
\hline & $(0.55)$ & $(0.65)$ & $(0.18)$ \\
\hline
\end{tabular}




\begin{tabular}{|c|c|c|c|}
\hline \multicolumn{4}{|l|}{ Breathing Health } \\
\hline \multirow[t]{2}{*}{ Female } & 1.007 & 1.008 & $1.020 * *$ \\
\hline & $(1.53)$ & $(1.61)$ & $(2.22)$ \\
\hline \multirow[t]{2}{*}{ Male } & $1.010 * *$ & $1.010 * *$ & $1.022 * * *$ \\
\hline & (1.99) & $(2.08)$ & (3.16) \\
\hline \multirow[t]{2}{*}{ Income below median } & 1.006 & $1.007 *$ & 1.005 \\
\hline & $(1.57)$ & $(1.67)$ & $(1.11)$ \\
\hline \multirow[t]{2}{*}{ Income above median } & $1.015^{* *}$ & $1.016 * *$ & $1.018 * *$ \\
\hline & $(2.43)$ & $(2.58)$ & $(2.25)$ \\
\hline \multicolumn{4}{|l|}{ Migraine Health } \\
\hline \multirow[t]{2}{*}{ Female } & $1.008 * * *$ & $1.010 * * *$ & $1.011 * * *$ \\
\hline & $(2.62)$ & $(3.11)$ & $(2.71)$ \\
\hline \multirow[t]{2}{*}{ Male } & 1.007 & 1.006 & 1.011 \\
\hline & $(0.99)$ & $(0.88)$ & $(0.93)$ \\
\hline \multirow[t]{2}{*}{ Income below median } & $1.008 * * *$ & $1.010 * * *$ & $1.012 * * *$ \\
\hline & $(2.75)$ & $(3.16)$ & $(3.44)$ \\
\hline \multirow[t]{2}{*}{ Income above median } & 1.009 & 1.009 & 1.005 \\
\hline & $(1.15)$ & $(1.17)$ & $(0.52)$ \\
\hline \multicolumn{4}{|l|}{ Skin/Allergy Health } \\
\hline \multirow[t]{2}{*}{ Female } & $1.010 * * *$ & $1.012 * * *$ & $1.020 * * *$ \\
\hline & $(3.01)$ & $(3.55)$ & $(4.09)$ \\
\hline \multirow[t]{2}{*}{ Male } & 1.007 & 1.008 & $1.019 * *$ \\
\hline & $(1.36)$ & $(1.45)$ & $(2.49)$ \\
\hline \multirow[t]{2}{*}{ Income below median } & $1.010 * * *$ & $1.012 * * *$ & $1.022 * * *$ \\
\hline & $(3.29)$ & $(3.68)$ & $(4.46)$ \\
\hline \multirow[t]{2}{*}{ Income above median } & 1.008 & 1.008 & 1.018 \\
\hline & $(1.11)$ & $(1.22)$ & $(1.32)$ \\
\hline \multicolumn{4}{|l|}{ 'Other' Health Conditions } \\
\hline \multirow[t]{2}{*}{ Female } & $1.009 * *$ & $1.010 * * *$ & $1.020 * * *$ \\
\hline & $(2.56)$ & $(2.71)$ & $(4.38)$ \\
\hline \multirow[t]{2}{*}{ Male } & 1.001 & 1.002 & 0.999 \\
\hline & $(0.15)$ & $(0.28)$ & $(-0.12)$ \\
\hline \multirow[t]{2}{*}{ Income below median } & $1.009 * *$ & $1.010 * * *$ & $1.018 * * *$ \\
\hline & $(2.49)$ & $(2.60)$ & $(3.21)$ \\
\hline \multirow[t]{2}{*}{ Income above median } & 1.005 & 1.006 & 1.007 \\
\hline & $(0.63)$ & $(0.77)$ & $(0.78)$ \\
\hline
\end{tabular}

Notes: Numbers in parentheses are asymptotic z-statistics. All coefficients have been converted to odds ratios. $*, * *$ and $* * *$ indicate $10 \%, 5 \%$ and $1 \%$ significance, respectively. All regressions include the covariates in Table 1. 
Table 4. Odds Ratio for Percent of Time Spent on Flexible Employment for those in Sample for at Least Five Waves

\begin{tabular}{lccc} 
& & \multicolumn{2}{c}{ Prentice-Gloeckler (hshaz) } \\
Sample & Cox & without frailty & with frailty \\
\hline Subjective Health & $1.012^{* * *}$ & $1.014^{* * *}$ & $1.025^{* * *}$ \\
& $(3.04)$ & $(4.68)$ & $(3.14)$ \\
Heart Health & 1.006 & 1.008 & 0.987 \\
& $(0.69)$ & $(0.94)$ & $(-0.80)$ \\
Stomach Health & $1.019^{* * *}$ & $1.021^{* * *}$ & $1.035^{* * *}$ \\
& $(3.22)$ & $(3.61)$ & $(4.36)$ \\
Anxiety/Depression Health & 1.006 & 1.008 & 0.996 \\
& $(0.64)$ & $(0.92)$ & $(-0.22)$ \\
Breathing Health & $1.019^{* * *}$ & $1.013^{* * *}$ & $1.029^{* * *}$ \\
& $(3.70)$ & $(2.69)$ & $(4.25)$ \\
Migraine Health & $1.016^{*}$ & $1.021 * *$ & $1.032^{* * *}$ \\
& $(1.76)$ & $(2.48)$ & $(2.99)$ \\
Skin/Allergy Health & 1.011 & $1.016^{* *}$ & $1.020^{*}$ \\
'Other' Health Conditions & $(1.50)$ & $(2.35)$ & $(1.91)$ \\
& $1.018^{* * *}$ & $1.020^{* * *}$ & $1.034^{* * *}$ \\
& $(3.80)$ & $(4.31)$ & $(4.18)$ \\
\hline
\end{tabular}

Numbers in parentheses are asymptotic z-statistics. All coefficients have been converted to odds ratios. $*, * *$ and $* * *$ indicate $10 \%, 5 \%$ and $1 \%$ significance, respectively. All regressions include the covariates in Table 1. 
Table 5. Odds Ratios for Regressions Allowing for Nonwork

Prentice-Gloeckler (hshaz)

Sample and Variable

$\operatorname{Cox}$ without frailty

with frailty

Subjective Health

$\%$ of time in flexible employment

$1.005 * * *$

(3.40)

$\%$ of time in nonwork

\section{Heart Health}

$\%$ of time in flexible employment

$\%$ of time in nonwork

Stomach Health

$\%$ of time in flexible employment

$\%$ of time in nonwork

\section{Anxiety/Depression Health}

$\%$ of time in flexible employment

$\%$ of time in nonwork

\section{Breathing Health}

$\%$ of time in flexible employment

$\%$ of time in nonwork

\section{Migraine Health}

$\%$ of time in flexible employment

$\%$ of time in nonwork

\section{Skin/Allergy Health}

$\%$ of time in flexible employment

$\%$ of time in nonwork

\section{'Other' Health Conditions}

$\%$ of time in flexible employment

$\%$ of time in nonwork
$0.991 * * *$

$(-9.22)$

$1.004^{*}$
$(1.50)$
$0.995 * * *$
$(-4.07)$

$1.014 * * *$

(6.26)

$0.994 * * *$

$(-3.66)$

$1.007 * * *$

$0.993 * * *$

$(-4.88)$

$1.006 * *$

(2.17)

$0.991 * * *$

$(-5.70)$

$1.006^{* *}$
$(2.25)$
$0.986 * * *$
$(-8.05)$

$1.007 * * *$
$(2.96)$
$0.990 * * *$
$(-7.10)$

1.004

$0.988 * * *$

(-7.78)

$1.005^{* * *}$
$(3.80)$
$0.990^{* * * *}$
$(10.17)$

$1.008 * * *$

(3.77)

$0.984 * * *$

$(-10.19)$

1.004

(1.20)

(1.59)

$0.990 * * *$

(-4.88)

(-4.13)

$1.017 * * *$

$0.990 * * *$

$(-4.75)$

$(-3.76)$

$1.009 * * *$

(3.20)

$0.989 * * *$

$(-5.23)$

$(-4.96)$

$1.010 * *$

(2.47)

$0.986^{* * *}$

0.991 ***

$(-5.84)$

$(-5.79)$

$1.007 * *$

$0.983 * * *$

(-7.92)

$(-8.30)$

$1.011 * * *$

(3.09)

$0.981 * * *$

(-7.49)

(-7.38)

1.004

(1.08)

(1.44)

$0.983 * * *$

(-7.61)

Numbers in parentheses are asymptotic z-statistics. All coefficients have been converted to odds ratios. ** and $* * *$ indicate $5 \%$ and $1 \%$ significance, respectively. All regressions include the covariates in Table 1. 
Table 6. Odds Ratios on Percent of Time Spent on a Flexible Contract Hazard Regressions for the Objective Health Measures Robustness Check Including Past Health

Prentice-Gloeckler (hshaz)

\begin{tabular}{|c|c|c|c|}
\hline Sample & Cox & without frailty & with frailty \\
\hline \multicolumn{4}{|l|}{ Subjective Health } \\
\hline \multirow[t]{2}{*}{ All Waves } & $1.006 * * *$ & $1.008 * * *$ & $1.013 * * *$ \\
\hline & (3.59) & $(4.20)$ & $(4.55)$ \\
\hline \multirow[t]{2}{*}{ Last 13 Waves } & $1.009 * *$ & $1.011 * * *$ & $1.012 * * *$ \\
\hline & $(2.55)$ & (2.99) & $(2.75)$ \\
\hline \multirow[t]{2}{*}{ With past health } & $1.010 * * *$ & $0.984 * * *$ & $1.011 * * *$ \\
\hline & $(2.67)$ & $(-9.01)$ & $(3.06)$ \\
\hline \multicolumn{4}{|l|}{ Heart Health } \\
\hline \multirow[t]{2}{*}{ All Waves } & $1.008 * *$ & $1.008 * *$ & $1.011 * *$ \\
\hline & $(2.02)$ & $(2.16)$ & $(1.96)$ \\
\hline \multirow[t]{2}{*}{ Last 13 Waves } & $1.015^{* * *}$ & $1.017 * * *$ & $1.031 * * *$ \\
\hline & $(4.53)$ & $(4.95)$ & $(4.26)$ \\
\hline \multirow[t]{2}{*}{ With past health } & $1.015^{* * *}$ & $1.017 * * *$ & $1.029 * * *$ \\
\hline & $(4.33)$ & $(4.88)$ & $(4.14)$ \\
\hline \multicolumn{4}{|l|}{ Stomach Health } \\
\hline \multirow[t]{2}{*}{ All Waves } & $1.012 * * *$ & $1.013 * * *$ & $1.018 * * *$ \\
\hline & $(3.96)$ & $(4.24)$ & $(4.05)$ \\
\hline \multirow[t]{2}{*}{ Last 13 Waves } & $1.020 * * *$ & $1.021 * * *$ & $1.032 * * *$ \\
\hline & $(7.83)$ & $(8.29)$ & $(7.16)$ \\
\hline \multirow[t]{2}{*}{ With past health } & $1.020 * * *$ & $1.019 * * *$ & $1.026 * * *$ \\
\hline & $(7.89)$ & $(7.28)$ & $(5.93)$ \\
\hline \multicolumn{4}{|c|}{ Anxiety/Depression Health } \\
\hline \multirow[t]{2}{*}{ All Waves } & $1.010 * * *$ & $1.010 * * *$ & $1.014 * * *$ \\
\hline & $(3.05)$ & $(3.32)$ & $(3.11)$ \\
\hline \multirow[t]{2}{*}{ Last 13 Waves } & $1.016 * * *$ & $1.017 * * *$ & $1.030 * * *$ \\
\hline & $(5.91)$ & $(6.50)$ & $(5.79)$ \\
\hline \multirow[t]{2}{*}{ With past health } & $1.016^{* * *}$ & $1.012 * * *$ & $1.014 * * *$ \\
\hline & $(5.85)$ & $(4.51)$ & $(3.39)$ \\
\hline \multicolumn{4}{|l|}{ Breathing Health } \\
\hline \multirow[t]{2}{*}{ All Waves } & $1.008 * *$ & $1.009 * * *$ & $1.010 * *$ \\
\hline & $(2.52)$ & $(2.63)$ & $(2.35)$ \\
\hline \multirow[t]{2}{*}{ Last 13 Waves } & $1.019 * * *$ & $1.020 * * *$ & $1.033 * * *$ \\
\hline & (6.89) & $(7.37)$ & $(7.63)$ \\
\hline \multirow[t]{2}{*}{ With past health } & $1.019 * * *$ & $1.016 * * *$ & $1.025 * * *$ \\
\hline & $(6.80)$ & $(5.71)$ & $(4.55)$ \\
\hline \multicolumn{4}{|l|}{ Migraine Health } \\
\hline \multirow{2}{*}{ All Waves } & $1.008 * * *$ & $1.009 * * *$ & $1.009 * * *$ \\
\hline & $(2.84)$ & $(3.21)$ & $(3.21)$ \\
\hline \multirow[t]{2}{*}{ Last 13 Waves } & $1.010 * * *$ & $1.011 * * *$ & $1.012 * * *$ \\
\hline & $(3.40)$ & $(3.84)$ & $(3.25)$ \\
\hline \multirow[t]{2}{*}{ With past health } & $1.010 * * *$ & $1.009 * * *$ & $1.007 *$ \\
\hline & $(3.45)$ & (2.89) & $(1.75)$ \\
\hline
\end{tabular}




\begin{tabular}{lccc} 
Skin/Allergy Health & & & \\
All Waves & $1.009 * * *$ & $1.010^{* * *}$ & $1.018 * * *$ \\
& $(3.24)$ & $(3.58)$ & $(4.12)$ \\
Last 13 Waves & $1.013^{* * *}$ & $1.015^{* * *}$ & $1.023^{* * *}$ \\
& $(5.55)$ & $(6.28)$ & $(6.24)$ \\
With past health & $1.013^{* * *}$ & $1.013 * * *$ & $1.018^{* * *}$ \\
& $(5.50)$ & $(5.43)$ & $(5.76)$ \\
'Other' Health Conditions & & & \\
All Waves & $1.008^{* *}$ & $1.009 * * *$ & $1.015 * * *$ \\
& $(2.42)$ & $(2.65)$ & $(3.20)$ \\
Last 13 Waves & $1.018^{* * *}$ & $1.019 * * *$ & $1.031 * * *$ \\
& $(5.52)$ & $(6.07)$ & $(5.59)$ \\
With past health & $1.019 * * *$ & $1.021 * * *$ & $1.032 * * *$ \\
& $(5.95)$ & $(6.41)$ & $(4.83)$ \\
\hline
\end{tabular}

Notes: Numbers in parentheses are asymptotic z-statistics. All coefficients have been converted to odds ratios. $* *$ and $* * *$ indicate $5 \%$ and $1 \%$ significance, respectively. All regressions include the covariates in Table 1. 'With Past Health' regression includes a dummy if ill health (specific to the illness) in the first four waves of the BHPS. 
Table 7. Odds Ratios on Percent of Time Spent on a Flexible Contract Hazard Regressions for the GHQ Stress Measures by Subsample

\begin{tabular}{|c|c|c|c|}
\hline \multirow[b]{2}{*}{ Health Illness and Sample } & \multirow[b]{2}{*}{ Cox } & \multicolumn{2}{|c|}{ Prentice-Gloeckler (hshaz) } \\
\hline & & without frailty & with frailty \\
\hline \multicolumn{4}{|l|}{ Sleep $(n=2,718)$} \\
\hline \multirow[t]{2}{*}{ Full sample } & $1.005 * * *$ & $1.006 * * *$ & $1.008 * * *$ \\
\hline & $(3.02)$ & $(3.76)$ & $(3.28)$ \\
\hline \multirow[t]{2}{*}{ Female } & $1.006 * * *$ & $1.008 * * *$ & $1.010 * * *$ \\
\hline & $(2.89)$ & $(3.65)$ & $(3.42)$ \\
\hline \multirow[t]{2}{*}{ Male } & 1.003 & 1.004 & 1.006 \\
\hline & $(1.04)$ & $(1.33)$ & $(0.85)$ \\
\hline \multirow[t]{2}{*}{ Income below median } & $1.007 * * *$ & $1.008 * * *$ & $1.010 * * *$ \\
\hline & $(3.52)$ & $(4.55)$ & $(3.82)$ \\
\hline \multirow[t]{2}{*}{ Income above median } & 0.999 & 1.000 & 1.002 \\
\hline & $(-0.21)$ & $(-0.10)$ & $(0.34)$ \\
\hline \multicolumn{4}{|l|}{ Decision Making $(n=2,608)$} \\
\hline \multirow[t]{2}{*}{ Full Sample } & $1.007 * * *$ & $1.007 * * *$ & $1.013 * * *$ \\
\hline & $(2.94)$ & $(3.14)$ & $(3.61)$ \\
\hline \multirow[t]{2}{*}{ Female } & 1.000 & 1.001 & 1.003 \\
\hline & $(0.11)$ & $(0.19)$ & $(0.53)$ \\
\hline \multirow[t]{2}{*}{ Male } & $1.023 * * *$ & $1.013 * * *$ & $1.024 * * *$ \\
\hline & $(4.27)$ & $(4.52)$ & $(5.10)$ \\
\hline \multirow[t]{2}{*}{ Income below median } & $1.005^{*}$ & $1.006 * *$ & $1.011 * * *$ \\
\hline & $(1.87)$ & $(2.12)$ & $(3.00)$ \\
\hline \multirow[t]{2}{*}{ Income above median } & $1.011 * *$ & $1.012 * * *$ & $1.022 * * *$ \\
\hline & $(2.56)$ & $(2.75)$ & $(4.09)$ \\
\hline \multicolumn{4}{|l|}{ Under Strain $(n=2,504)$} \\
\hline \multirow[t]{2}{*}{ Full Sample } & $1.004 * *$ & $1.005 * * *$ & $1.006 * * *$ \\
\hline & $(2.58)$ & $(3.30)$ & $(2.71)$ \\
\hline \multirow[t]{2}{*}{ Female } & $1.004 *$ & $1.005 * *$ & $1.008 * *$ \\
\hline & $(1.91)$ & $(2.30)$ & $(2.58)$ \\
\hline \multirow[t]{2}{*}{ Male } & $1.005 * *$ & $1.006 * * *$ & $1.009 *$ \\
\hline & $(1.96)$ & $(2.63)$ & $(1.69)$ \\
\hline \multirow[t]{2}{*}{ Income below median } & $1.004 *$ & $1.005 * *$ & $1.009 * * *$ \\
\hline & $(1.91)$ & $(2.50)$ & $(2.68)$ \\
\hline \multirow[t]{2}{*}{ Income above median } & $1.005^{*}$ & $1.006 * *$ & 1.004 \\
\hline & $(1.75)$ & $(2.37)$ & $(1.22)$ \\
\hline \multicolumn{4}{|c|}{ Overcome Difficulties $(n=2,668)$} \\
\hline \multirow[t]{2}{*}{ Full Sample } & $1.008 * * *$ & $1.009 * * *$ & $1.015^{* * *}$ \\
\hline & $(5.13)$ & $(5.84)$ & $(4.63)$ \\
\hline \multirow[t]{2}{*}{ Female } & $1.010 * * *$ & $1.012^{* * *}$ & $1.018 * * *$ \\
\hline & $(4.91)$ & $(5.63)$ & $(4.74)$ \\
\hline Male & $1.006 * *$ & $1.007 * * *$ & 1.008 \\
\hline & $(2.41)$ & $(2.75)$ & $(1.57)$ \\
\hline Income below median & $1.008 * * *$ & $1.009 * * *$ & $1.014 * * *$ \\
\hline & $(4.34)$ & $(5.09)$ & $(3.86)$ \\
\hline Income above median & $1.010 * * *$ & $1.011 * * *$ & $1.021 * * *$ \\
\hline & $(2.83)$ & $(3.21)$ & $(4.49)$ \\
\hline
\end{tabular}




\begin{tabular}{lccc} 
Lose Confidence $(n=2,620)$ & & \\
Full Sample & $1.007^{* * *}$ & $1.007^{* * *}$ & $1.011^{* * *}$ \\
& $(3.50)$ & $(3.84)$ & $(3.96)$ \\
Female & $1.005^{* *}$ & $1.006^{* *}$ & 1.008 \\
& $(2.04)$ & $(2.29)$ & $(1.43)$ \\
Male & $1.009^{* * *}$ & $1.010^{* * *}$ & $1.015^{* * *}$ \\
& $(3.04)$ & $(3.30)$ & $(3.44)$ \\
Income below median & $1.005^{* *}$ & $1.006^{* *}$ & $1.009^{* *}$ \\
& $(2.16)$ & $(2.46)$ & $(2.15)$ \\
Income above median & $1.012^{* * *}$ & $1.013^{* * *}$ & $1.018^{* * *}$ \\
& $(3.53)$ & $(3.91)$ & $(4.34)$ \\
Happiness $(n=2,663)$ & & & \\
Full Sample & $1.006^{* * *}$ & $1.007^{* * *}$ & $1.011^{* * *}$ \\
& $(3.42)$ & $(3.99)$ & $(4.00)$ \\
Female & $1.006^{* *}$ & $1.006^{* * *}$ & $1.011^{* * *}$ \\
& $(2.55)$ & $(3.03)$ & $(2.67)$ \\
Male & $1.007^{* * *}$ & $1.008^{* * *}$ & $1.012^{* *}$ \\
& $(2.61)$ & $(3.10)$ & $(2.57)$ \\
Income below median & $1.005^{* *}$ & $1.006^{* * *}$ & $1.009^{* * *}$ \\
Income above median & $(2.49)$ & $(2.99)$ & $(2.92)$ \\
& $1.008^{* *}$ & $1.009^{* * *}$ & $1.019^{* * *}$ \\
& $(2.53)$ & $(3.05)$ & $(4.42)$ \\
\hline
\end{tabular}

Notes: Numbers in parentheses are asymptotic z-statistics. All coefficients have been converted to odds ratios. $*$, ** and $* * *$ indicate $10 \%, 5 \%$ and $1 \%$ significance, respectively. All regressions include the covariates in Table 1. 
Figure 1: Survival Plot for Subjective Health

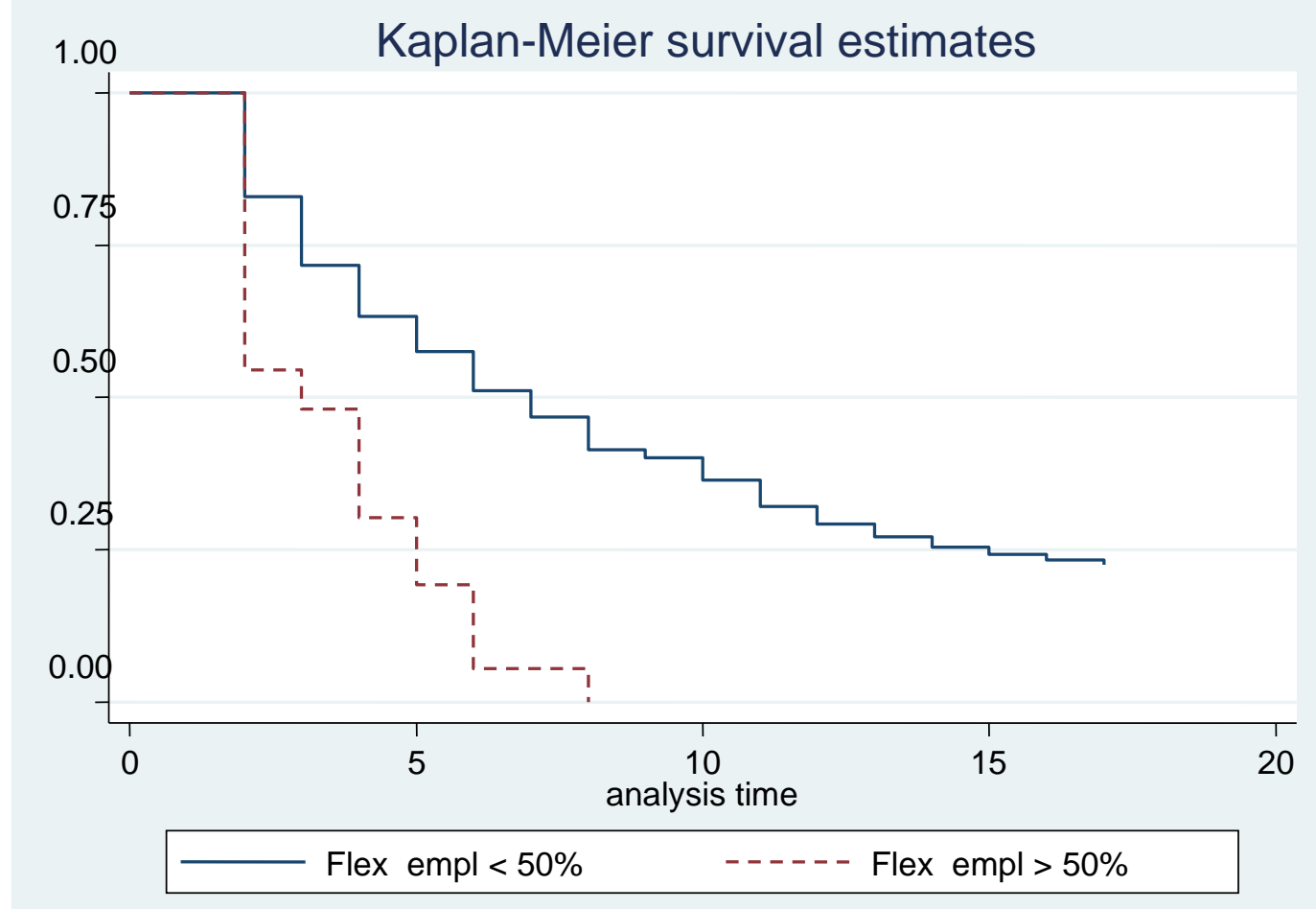

Figure 2: Survival Plot for Heart Health

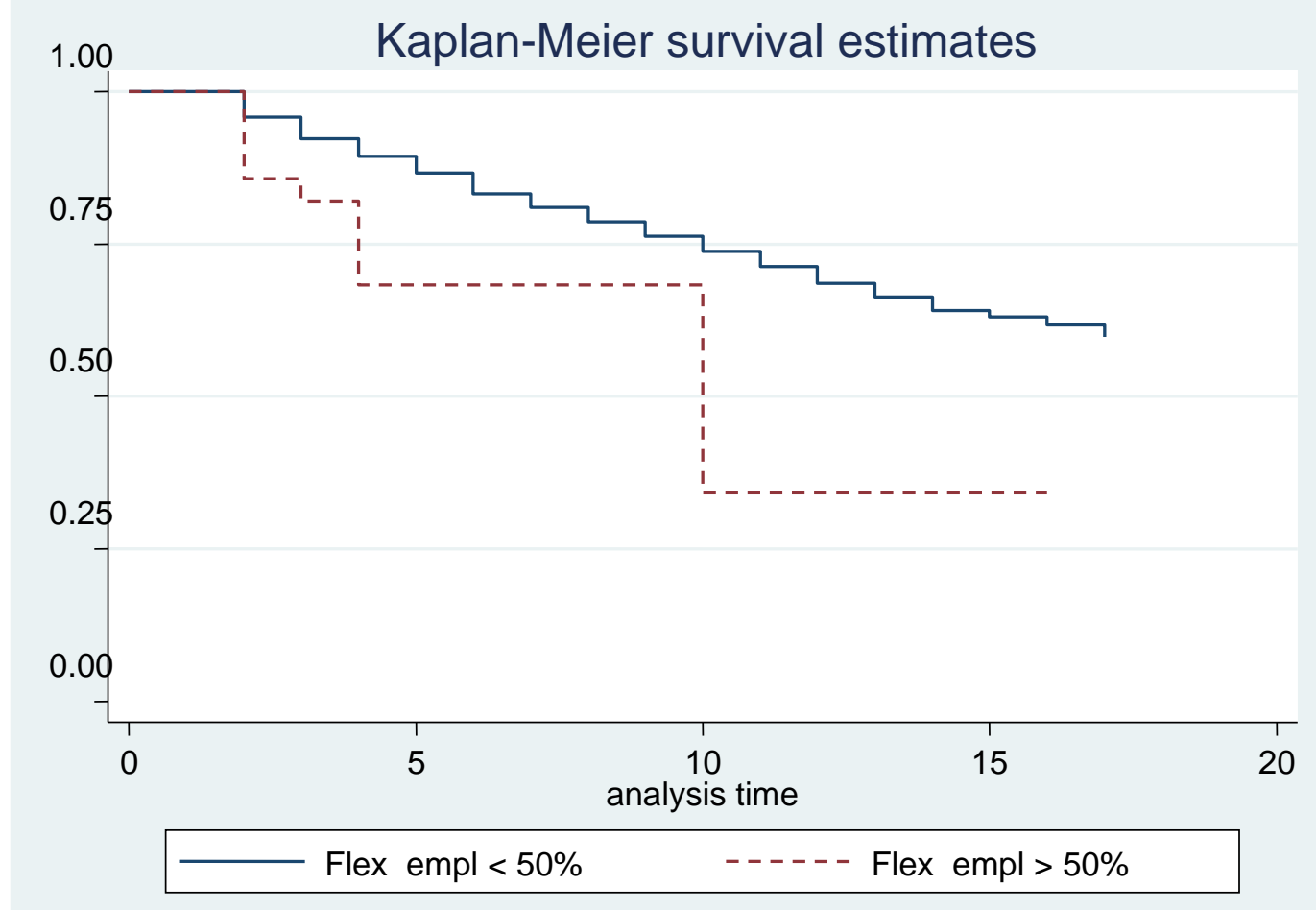


Figure 3. Survival Plot for Stomach Health

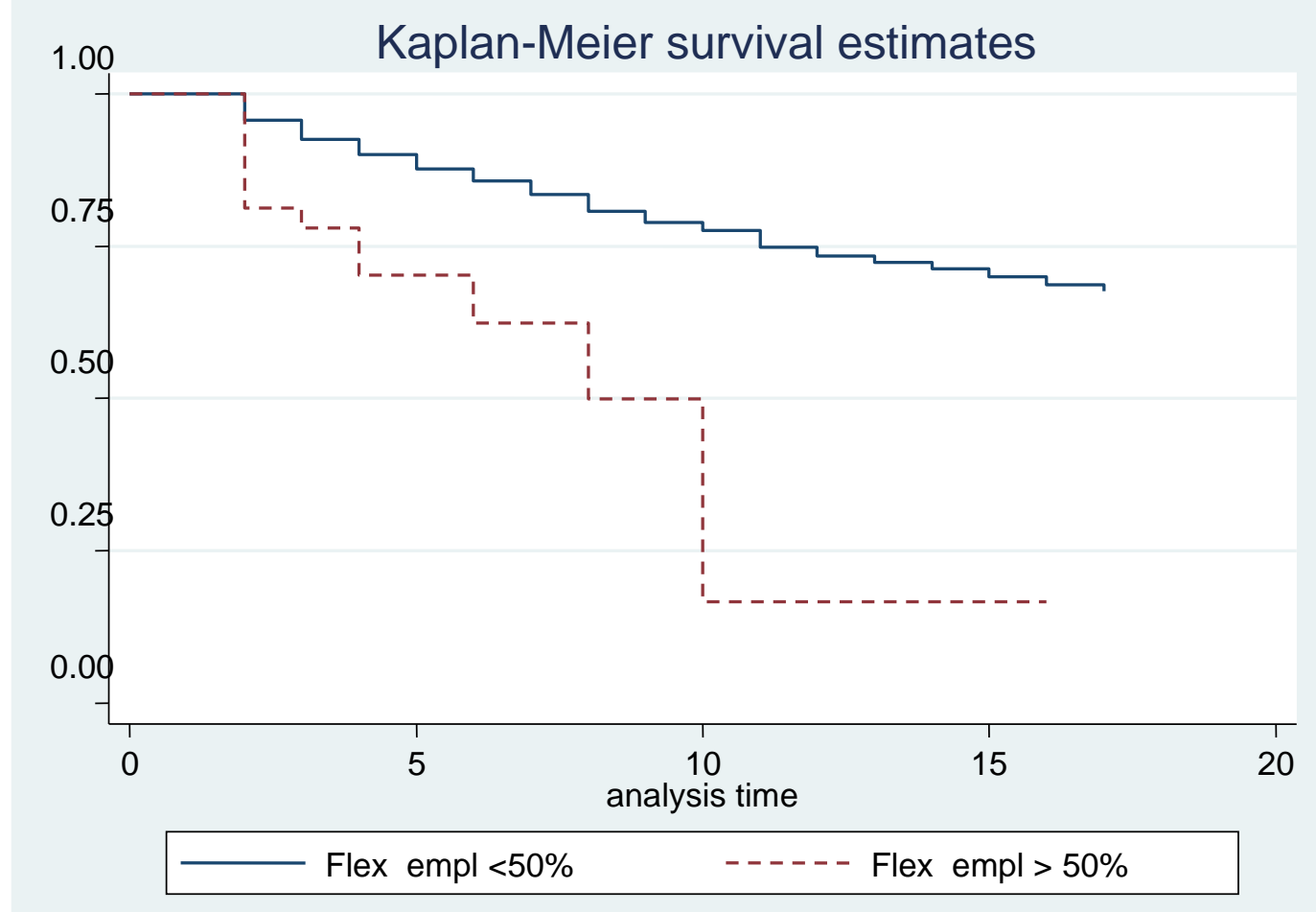

Figure 4. Survival Plot for Anxiety/Depression Health

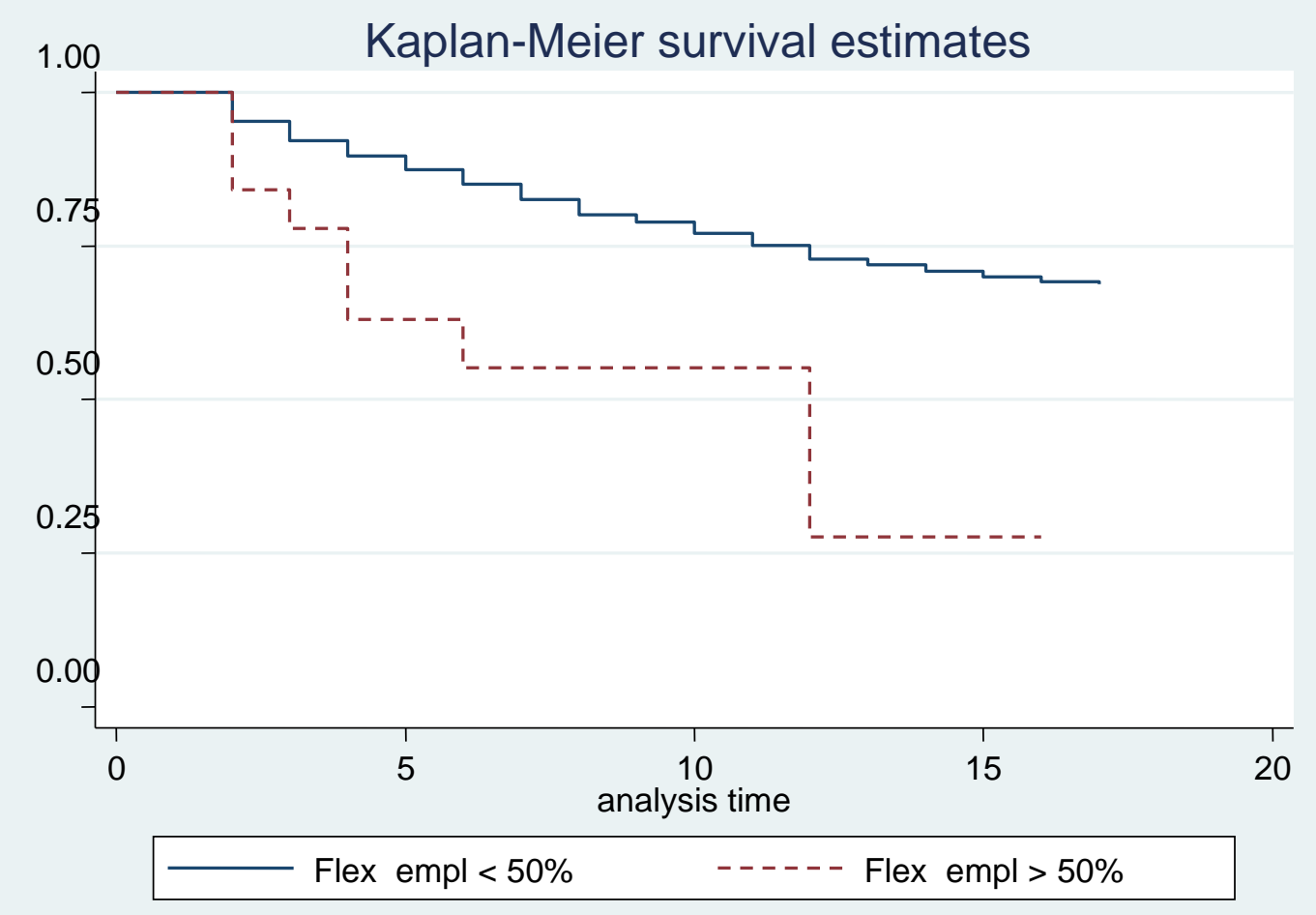


Figure 5. Survival Plot for Breathing Health

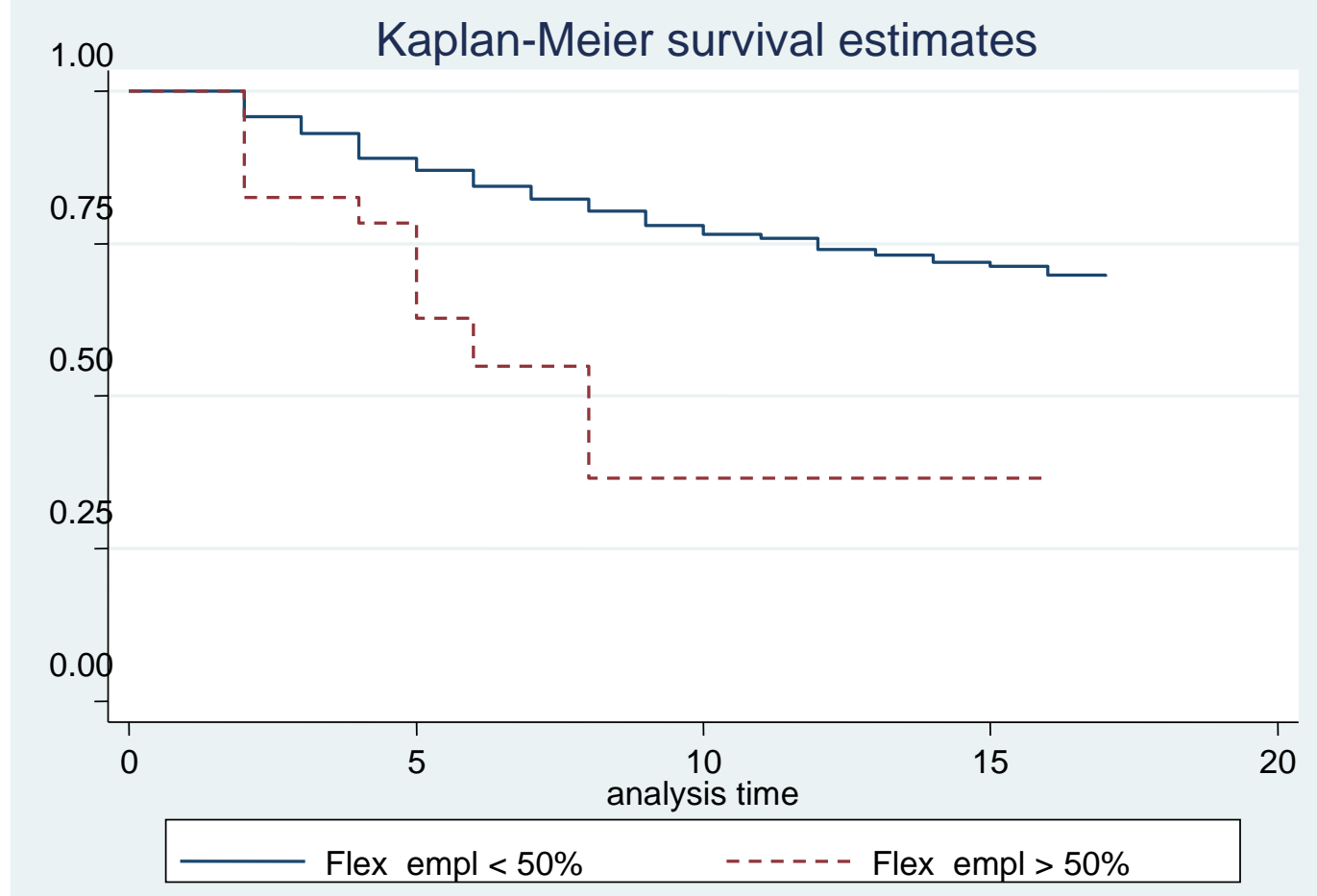

Figure 6. Survival Plot for Migraine Health

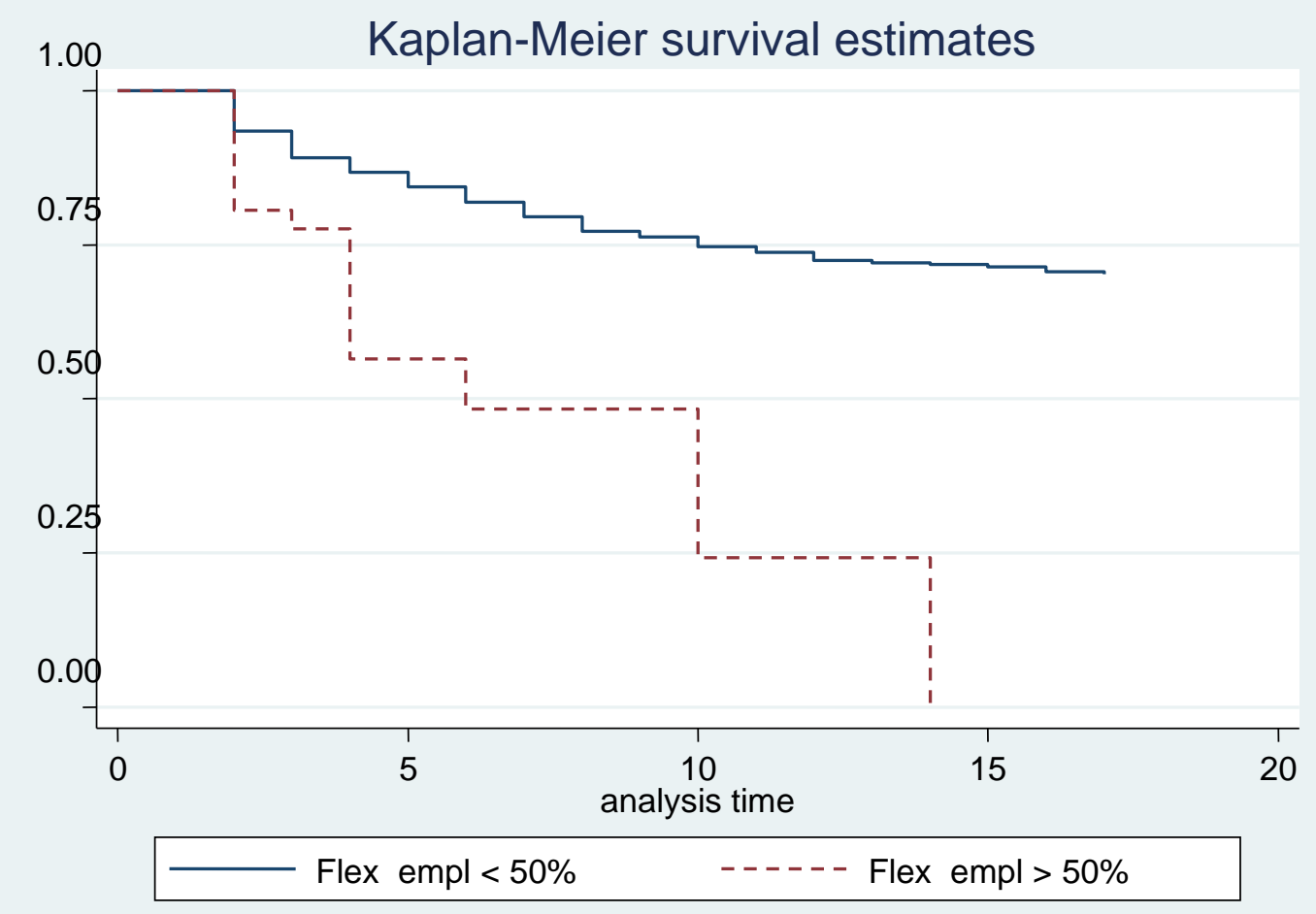


Figure 7. Survival Plot for Skin/Allergy Health

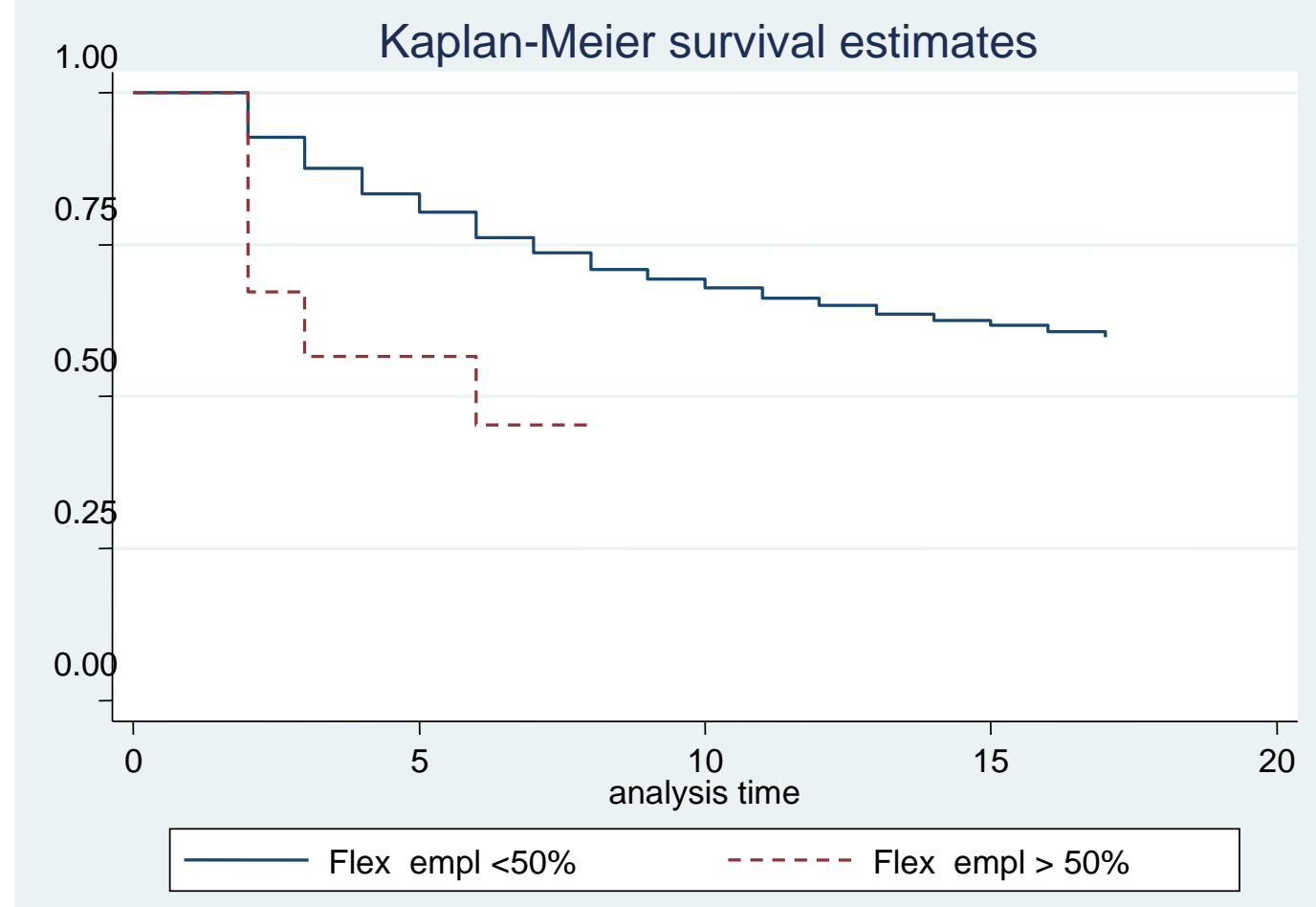

Figure 8. Survival Plot for 'Other' Health Conditions

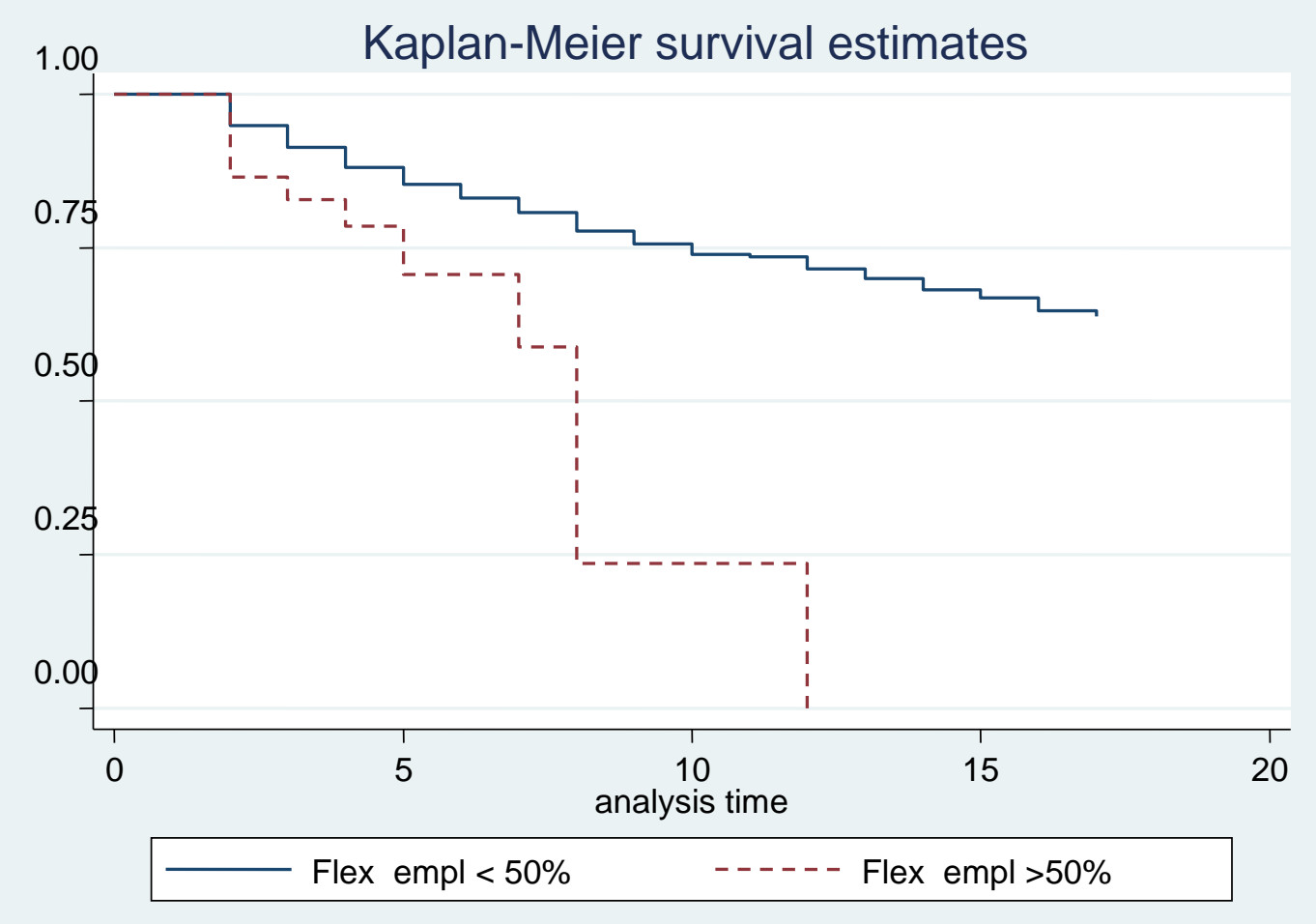


Figure 9. Kaplan-Meier Survival Estimates for Health Measures for Sample who Starts as Healthy and in a Permanent Contract Job

\section{Subjective Health}

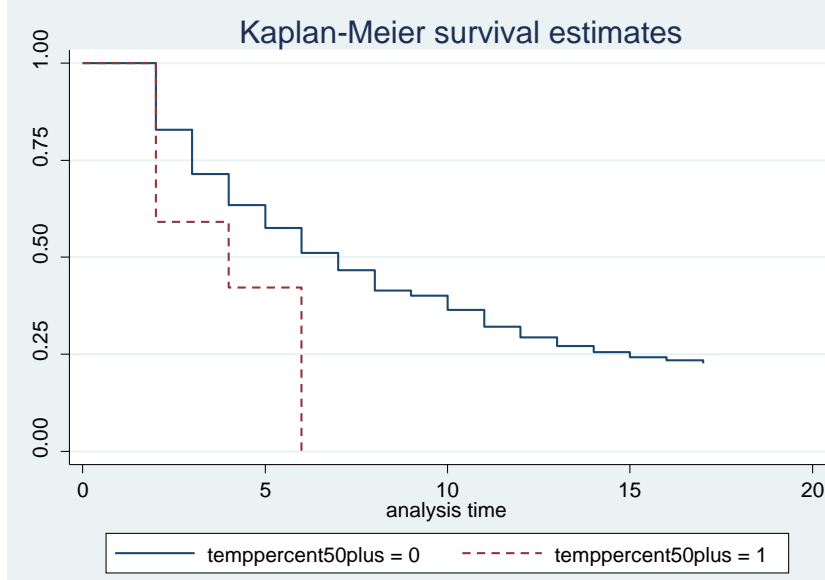

\section{Anxiety Health}

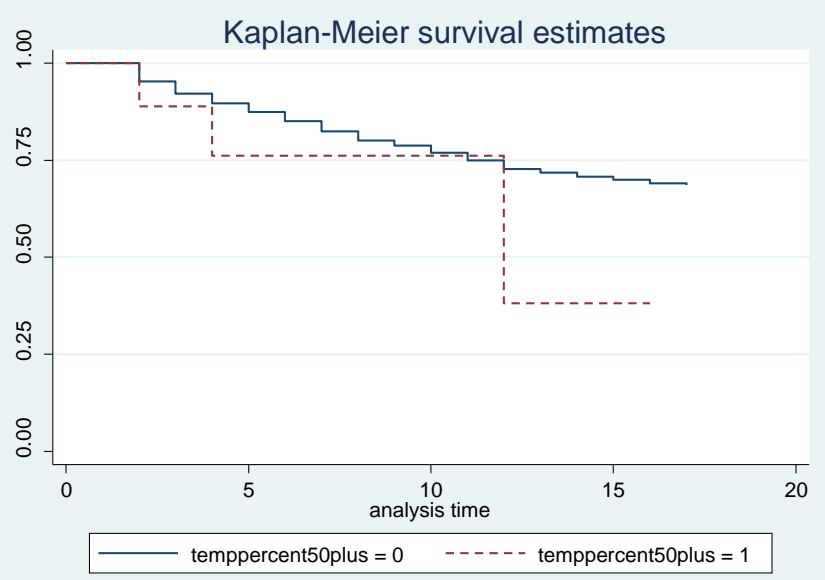

Heart Health

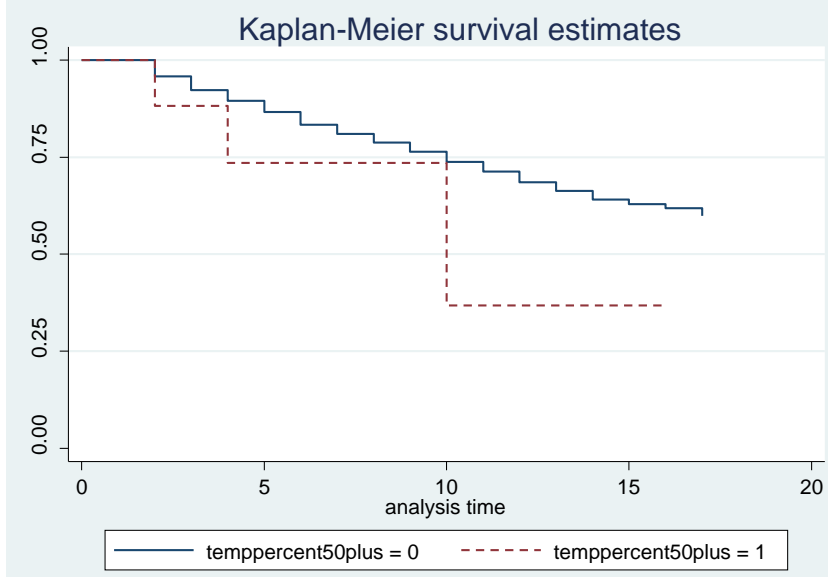

Breathing Health

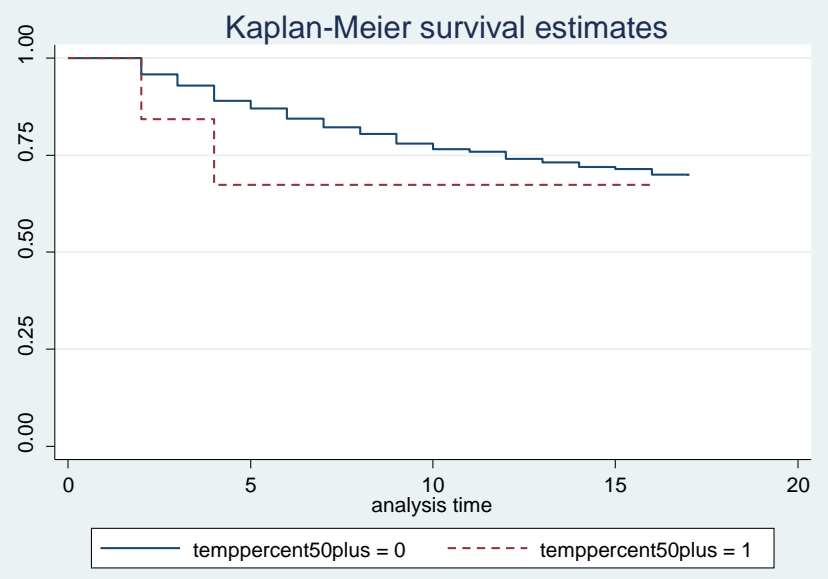

Migraine Health

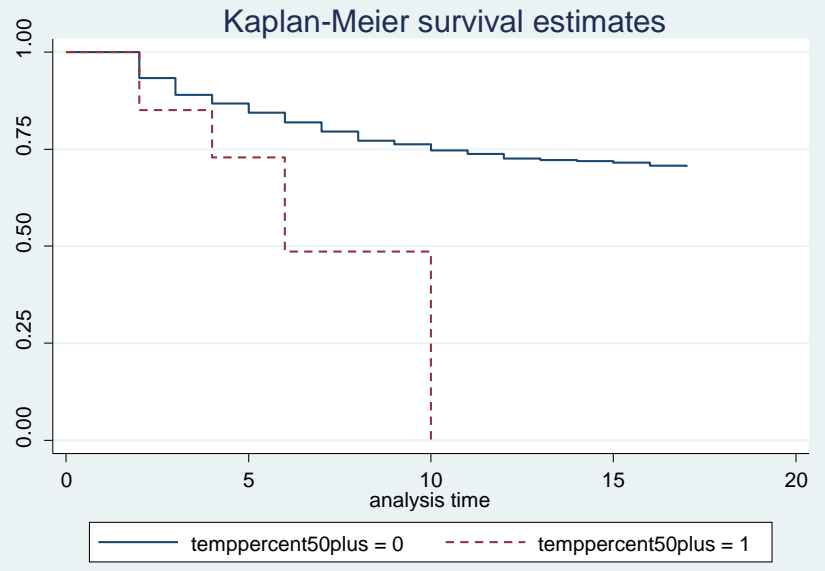




\section{Skin Health}

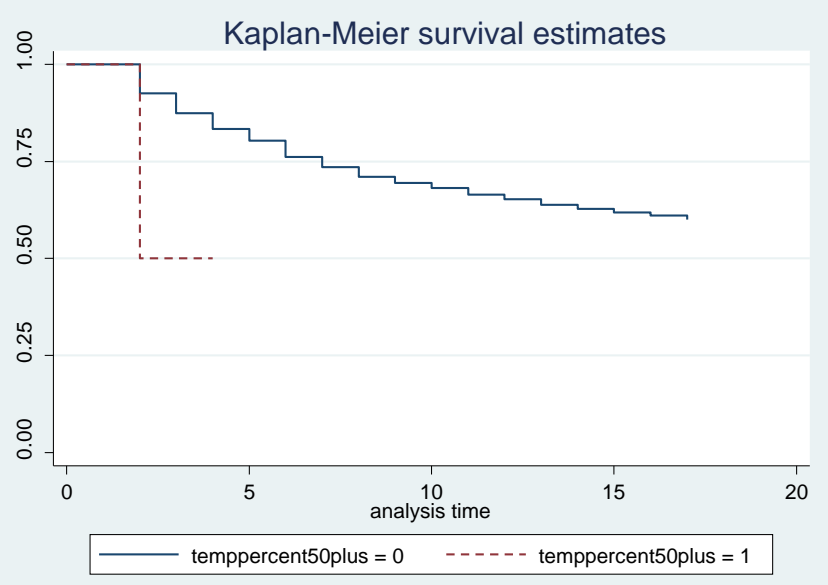

\section{Other Health}

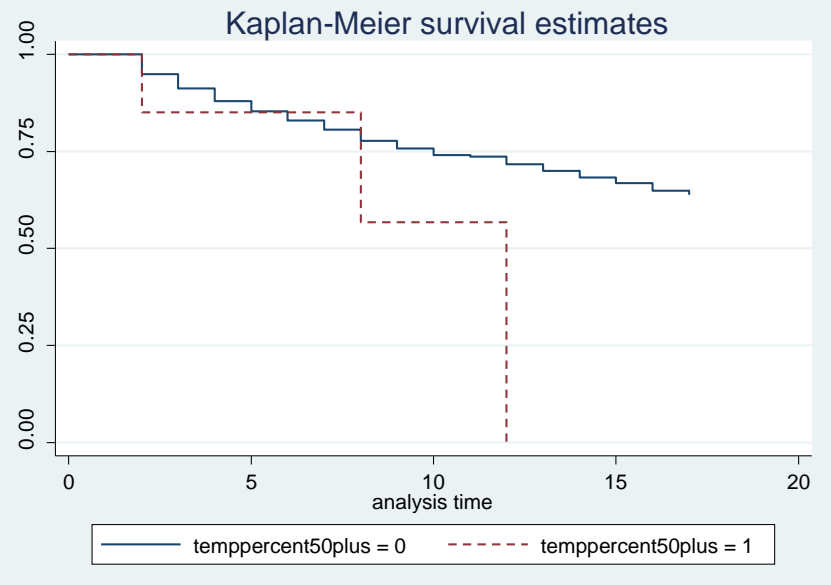

